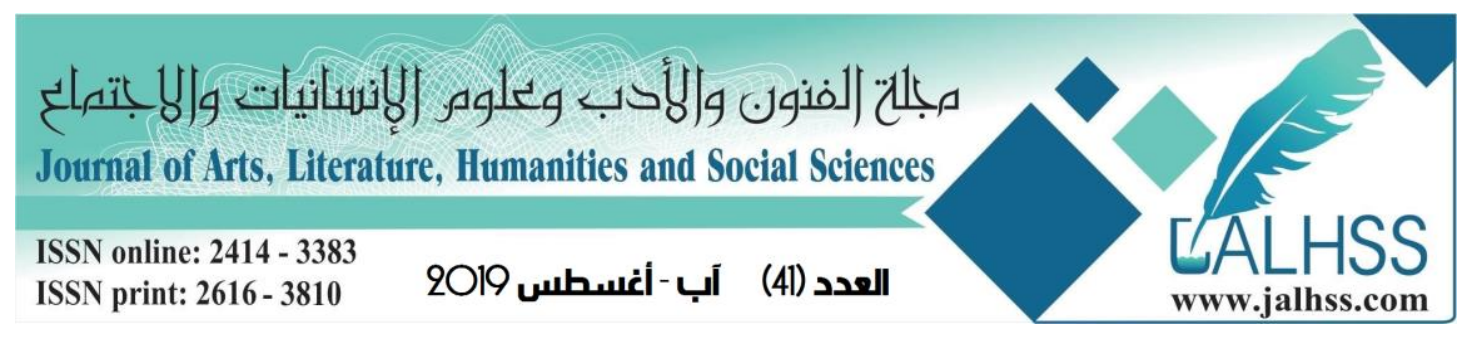

\title{
محمّد عبد الخالق عضيمة وجهوده التّحوية
}

\author{
م.د. انتصار يونس مهيهي \\ قسم اللغة العربية \\ كلية التربية للعلوم الإنسانيةـ جامعة ديالى العية \\ العراق الإن \\ entisaryounis6@Gmail.com
}

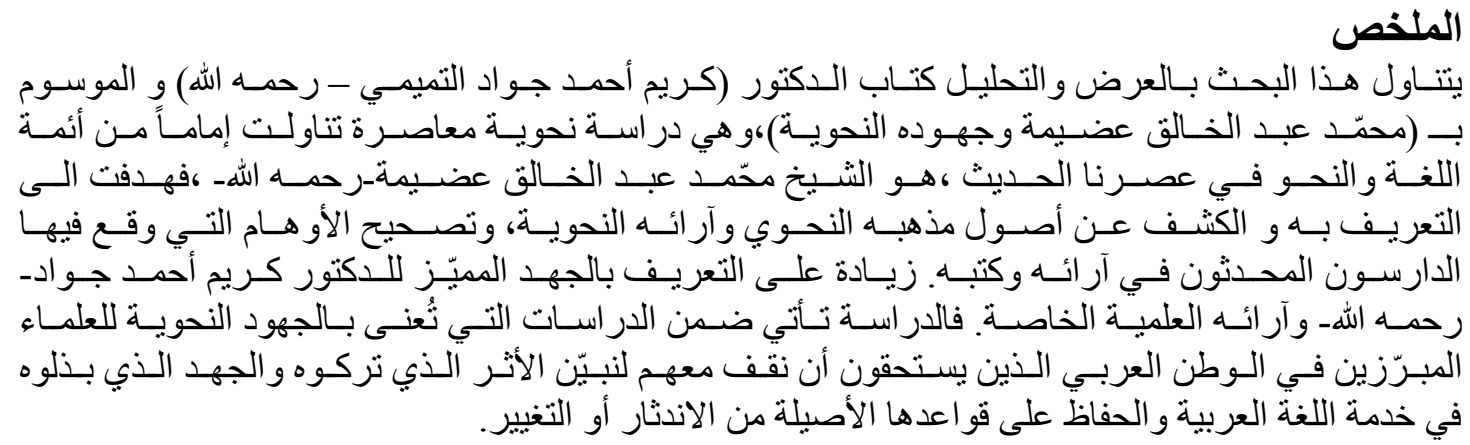

\section{Mohammed Abdulkhaliq and His Grammatical Contributions}

\author{
Ins. IntiasrYounis (Ph.D.) \\ University of Diyala / College of Education for Humanities
}

\begin{abstract}
This study is a presentation and an analysis of a modern grammatical study submitted by Dr. Kareem Ahmed Jawad Al Tamimi entitled "Mohammed Abdulkhaliq and His Grammatical Contributions". The contributions of this figure in modern linguistics and grammar were studied. The origins of his grammatical methodology were discovered. His grammatical opinions were corrected as there were many misconceptions about them that many scholars had mistaken. This study is one of the modern grammatical studies representing one of its figures in Iraq and Arab Homeland.
\end{abstract}




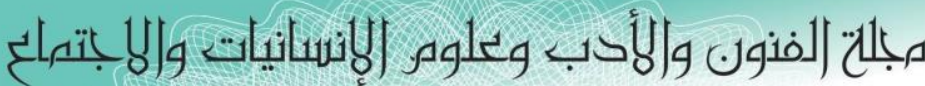

Journal of Arts, Literature, Humanities and Social Sciences

ISSN online: 2414 - 3383

ISSN print: 2616 - 3810

\section{العدد (41) آب - أغسطس 2019}

¿ALLHSS

wWw.jalhss.com

المقدمة

الحمدُ له المنعوت بجميل الصفات ،وصلّّى اللهُ تعالى على سيدنا محمٍٍّ المبعوثِ رحمةً للكائنات ،و على آله

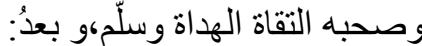

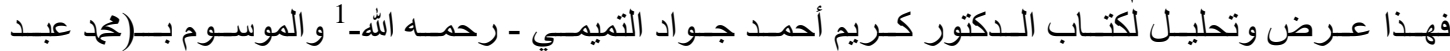

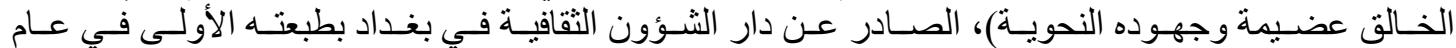

2008 مهوقد وقع في (320)صفحةٍة.

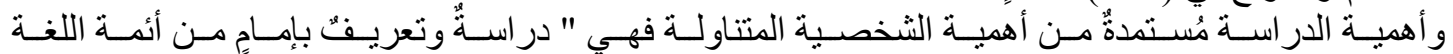

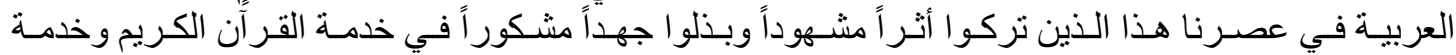

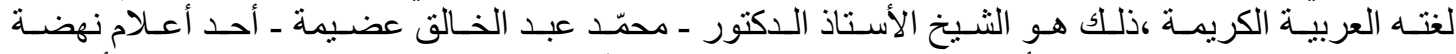

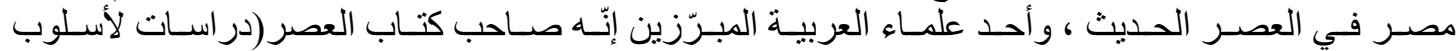

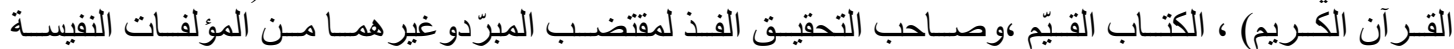

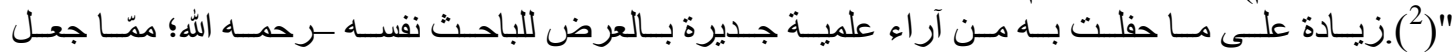

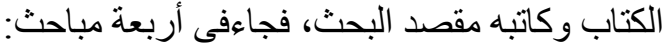

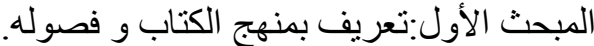

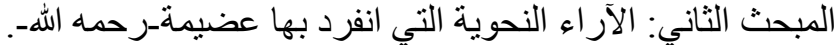
المبحث الثالث:تصحيح أو هام بعض الباحثين في آثار الثيخ عضيمة الثية-رحمه اللهـ و آرائه.

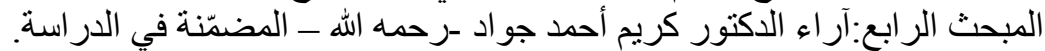
وختم البحث بخاتمة حوت الهم النتائج المستقاة من البحث، الهُ الله ولي التوفيق.

\section{المبحث الأول \\ تعريف بمنهج الكتاب وفصوله}

قام الكتاب على منهج تكاملي يجمع بين مناهج البحث المتنو عة ليقدّم در اسة علمية ر ائدة في ميدانها،فنر اه يعمد في

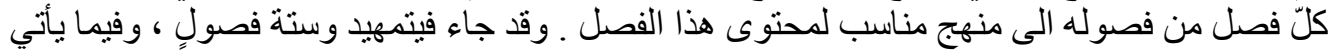
عرضها: التمهيد: (الترضيا:

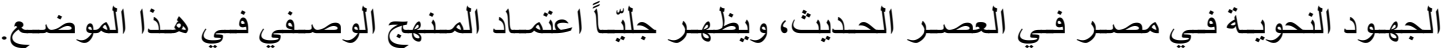

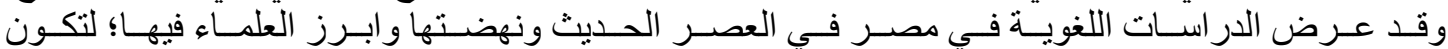

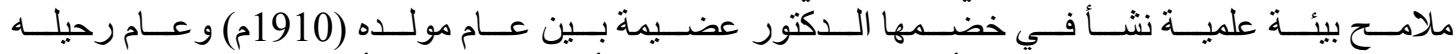

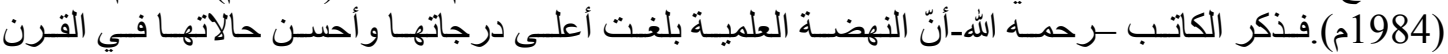

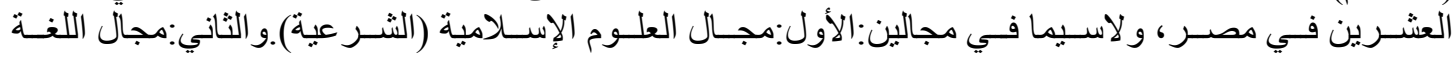
الأذي شمل نو عين من الدر اسات:

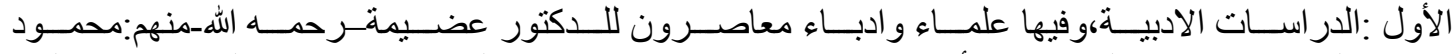

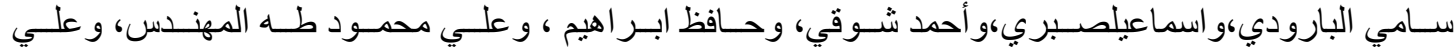

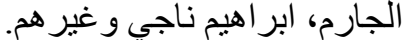

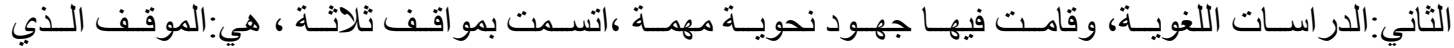

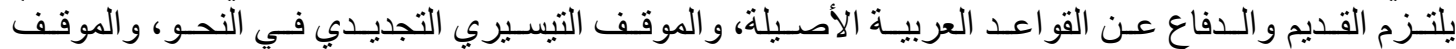

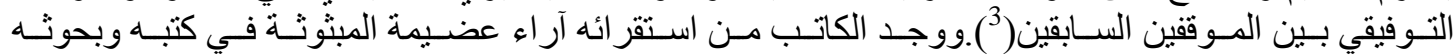

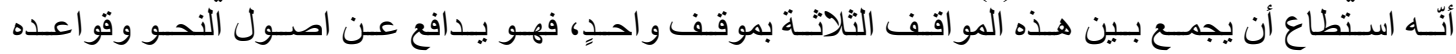

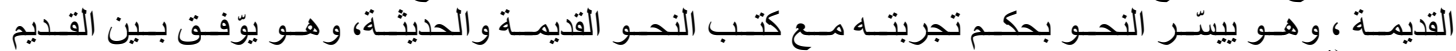

و الحديث) 


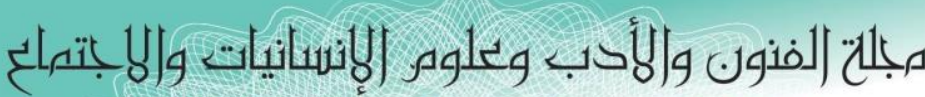
Journal of Arts, Literature, Humanities and Social Sciences

ISSN online: 2414 - 3383

ISSN print: 2616 - 3810

\section{العدد (41) آب - أغسطس 2019}

LALHSS

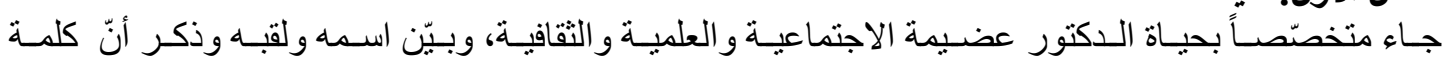

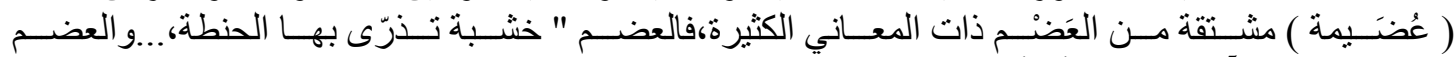

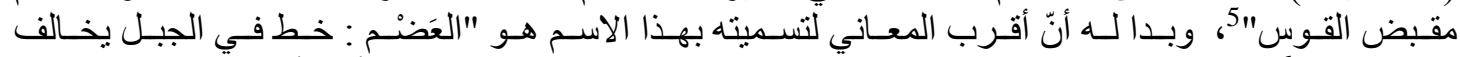

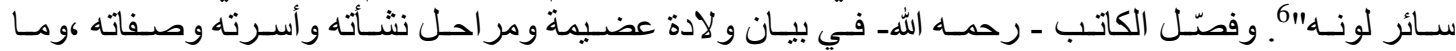

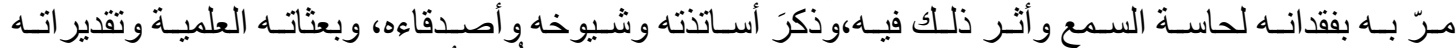

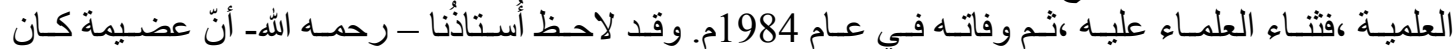

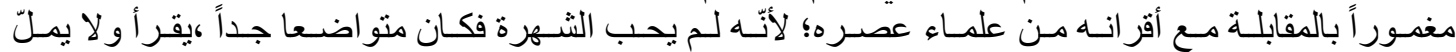
القر اءة ولا يُرى إلا في المكتبات.

الفصل الثاني: آثاره العلمية

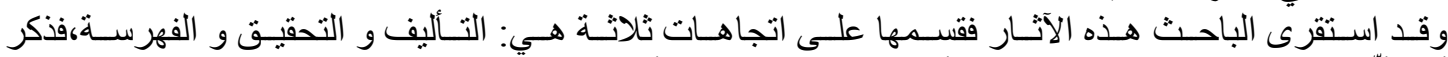

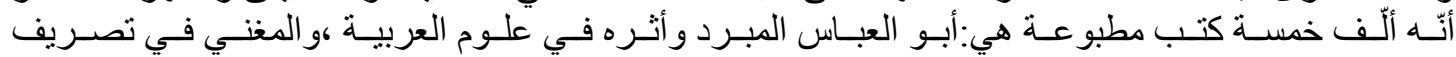

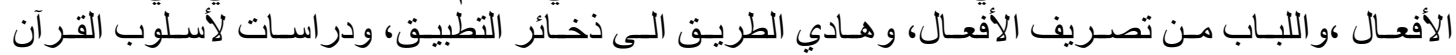

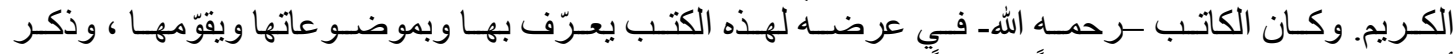

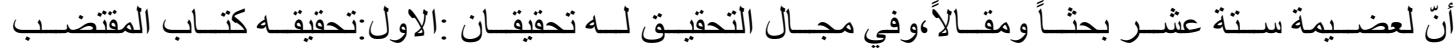

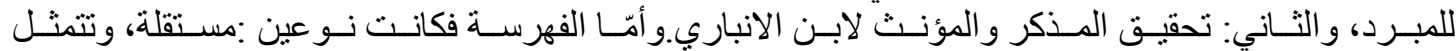

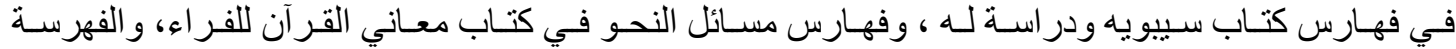

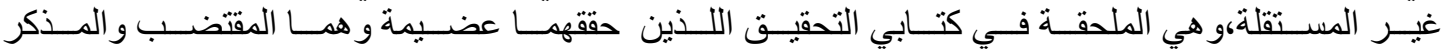

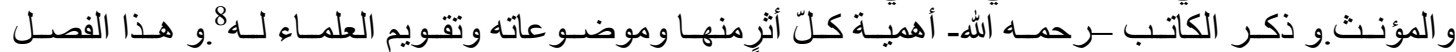

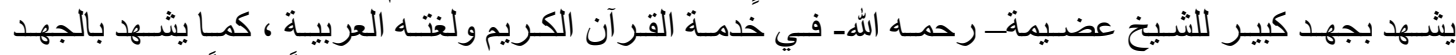

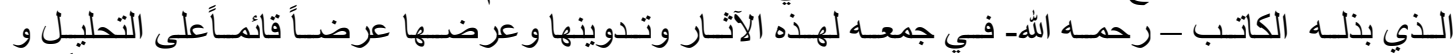

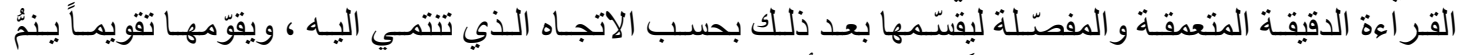

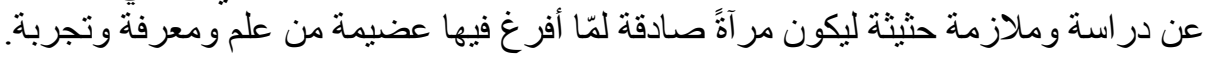

الفصل الثالث: مصادر عضيمة في دراساته النحوية

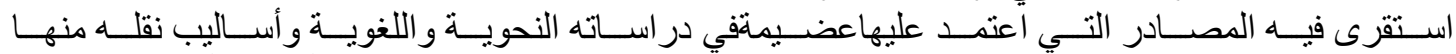

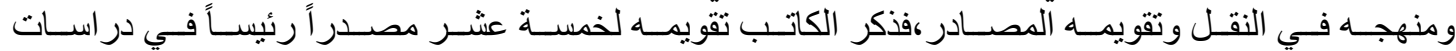

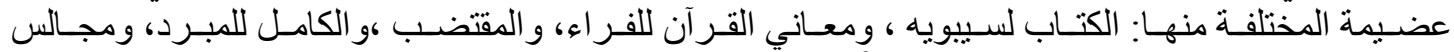

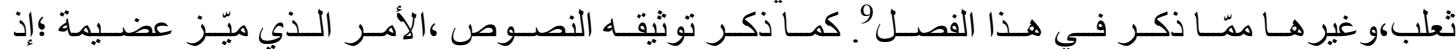

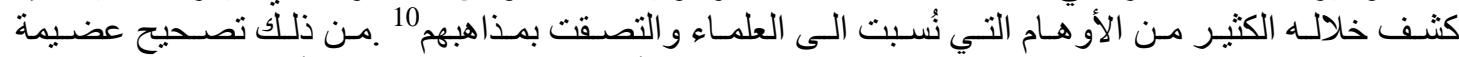

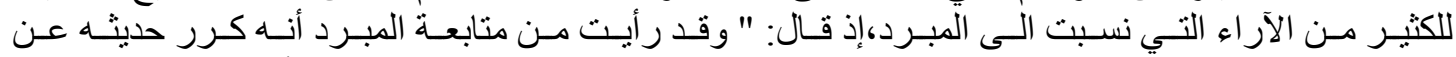

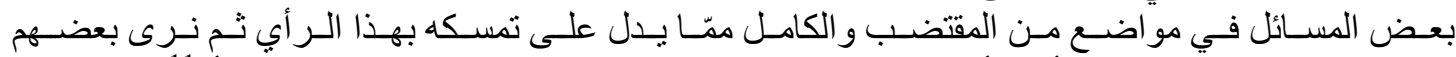

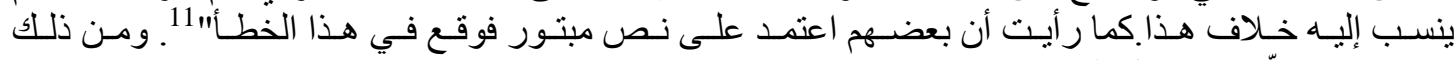
ماذكره عن (قلّما) في قول هذا الثاعر:

\section{صددت فأطولت الصدود وقلّما وصال على طول الصدود يدوم}

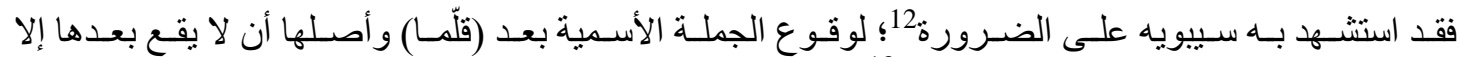

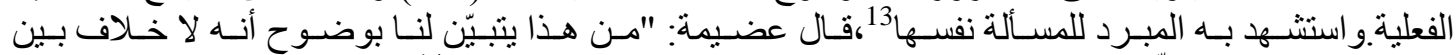

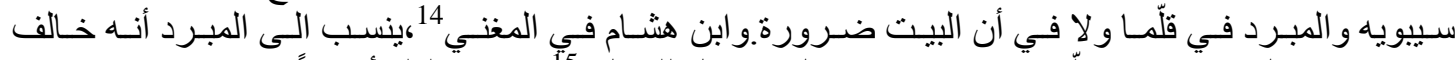

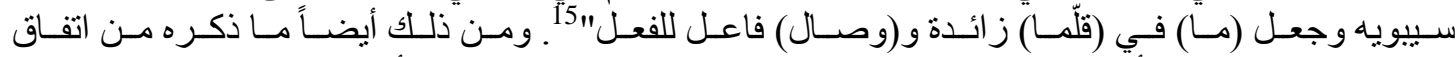

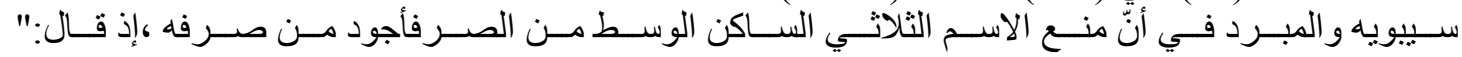




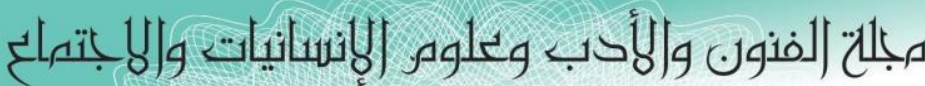

Journal of Arts, Literature, Humanities and Social Sciences

ISSN online: 2414 - 3383

ISSN print: 2616 - 3810

\section{العدد (41) آب - أغسطس 2019}

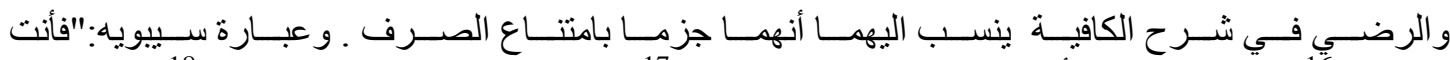

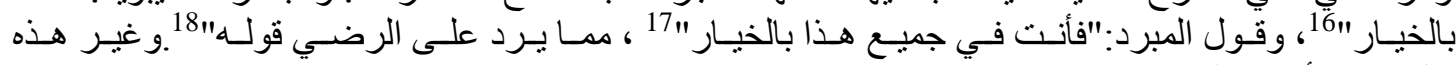

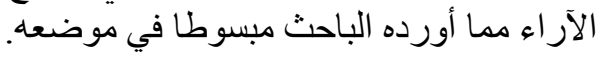

\section{الفصل الرابع: مذهبه النحوي وآراؤه النحوية}

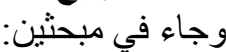

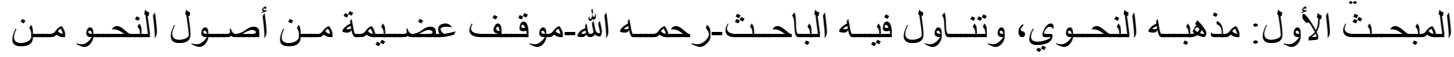

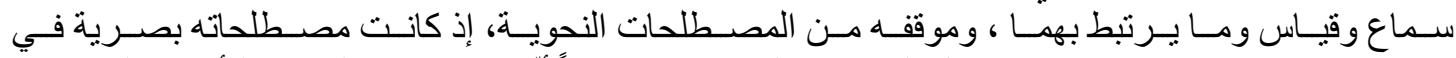

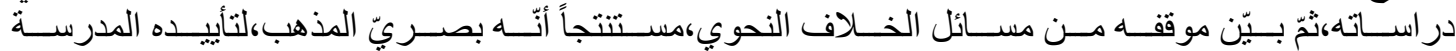

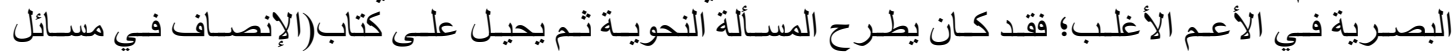

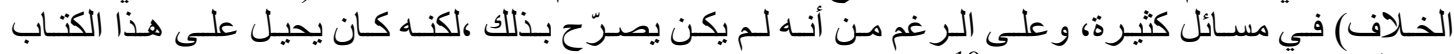
الذي أيّد البصري في مين في معظم المسائل 19.

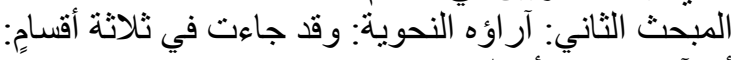

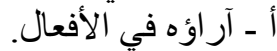

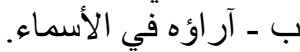
ج - آراؤه في الأدوات في و الحروف 20.

الفصل الخامس: موقف عضيمة من التيسير النحوي

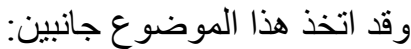

الأول: نقده الكتب التيسيرية المختلفة، وفيه ظهر دفاعه التهن عن القواعد العربية الأصيلة.

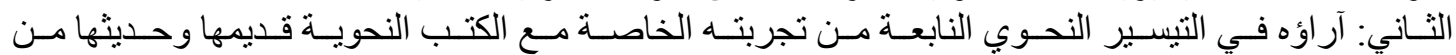

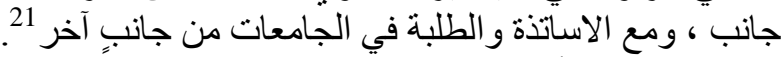

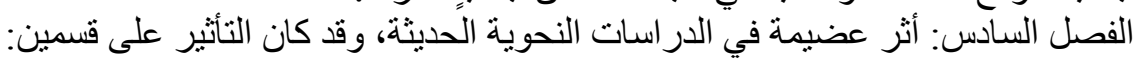

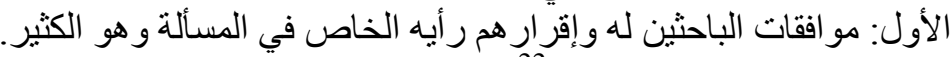

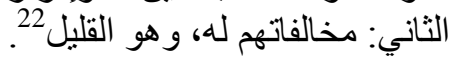

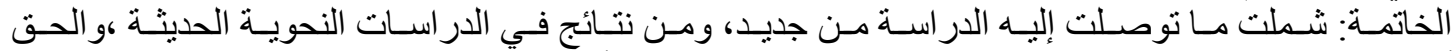

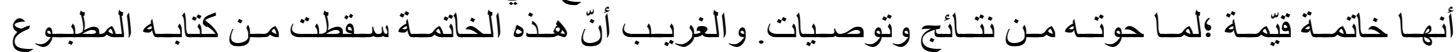

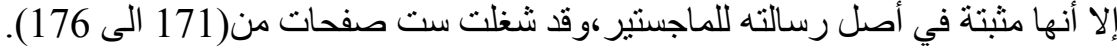

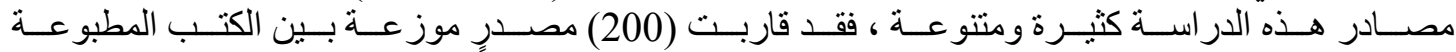

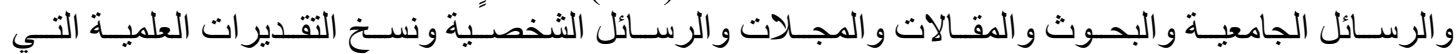

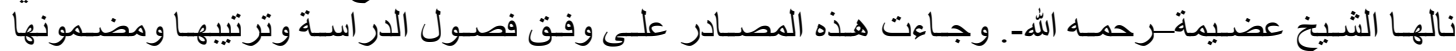

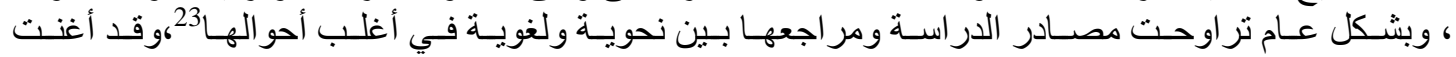

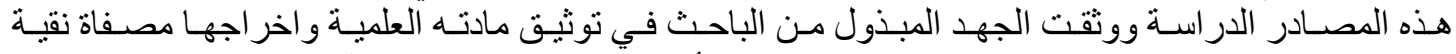

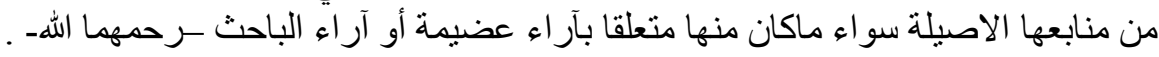

\section{الآراء التي انفرد بها عضيمة الثانيةرحمه الله-}

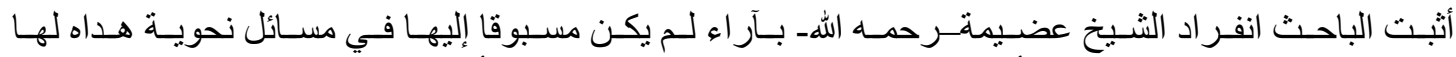
الاحصاء للقر آن الكريم و استقر اء أساليبه و الكتب النحوية الفئ قديمها وحديثها، سأذكر منها: 


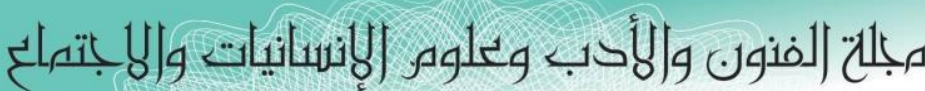

Journal of Arts, Literature, Humanities and Social Sciences

ISSN online: 2414 - 3383

ISSN print: 2616 - 3810

\section{العدد (41) آب - أغسطس 2019}

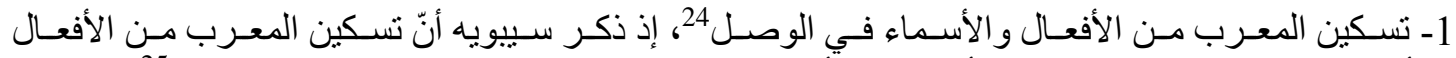

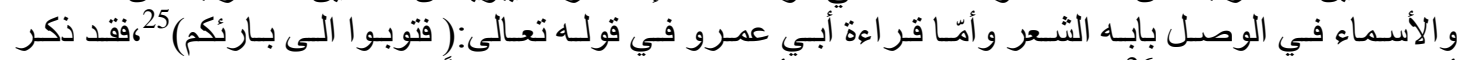

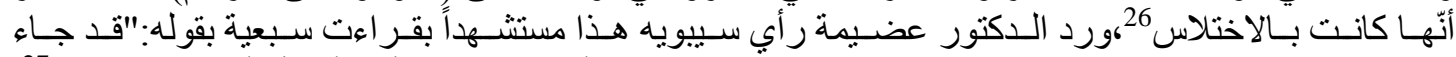

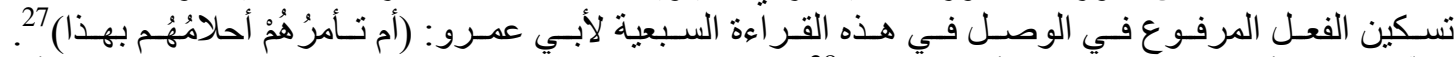

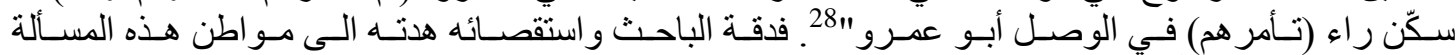
في كتب عضيمة مثبتاً انفر اده بهذا الرها الر أي .

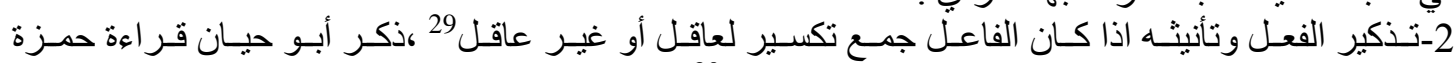

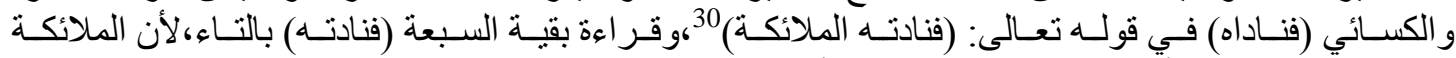

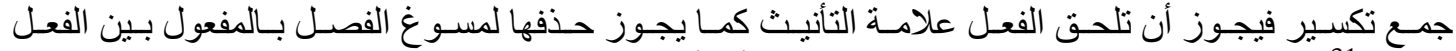

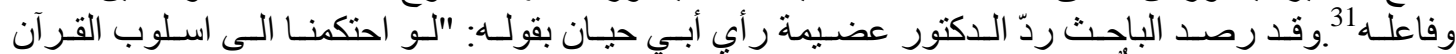

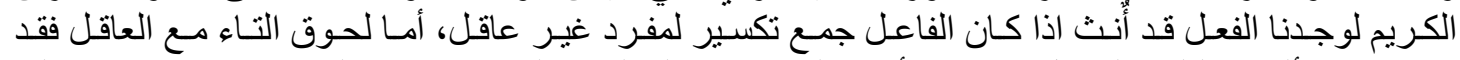

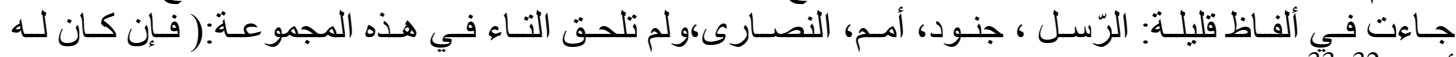
أخوة)32"3

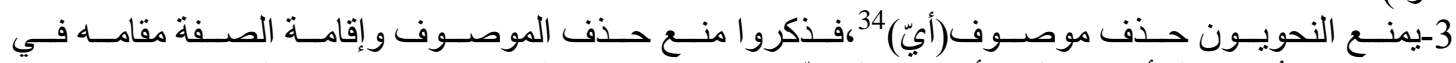

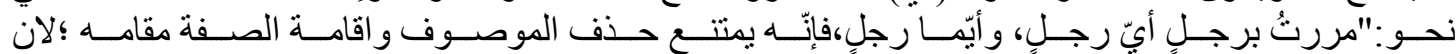

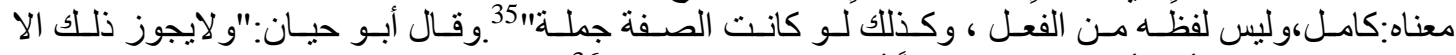

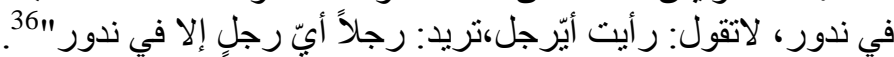

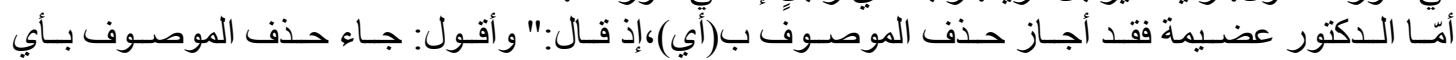

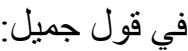

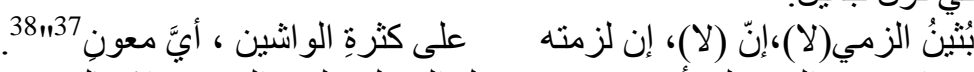

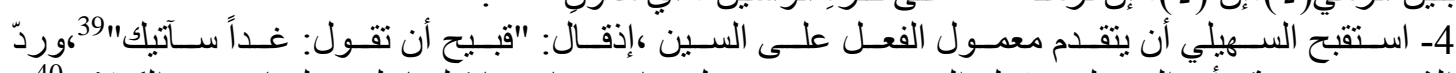

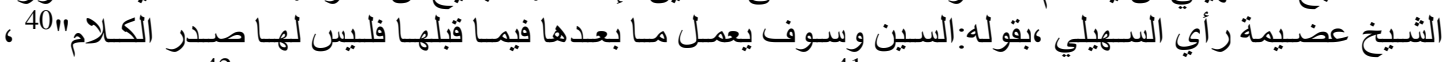

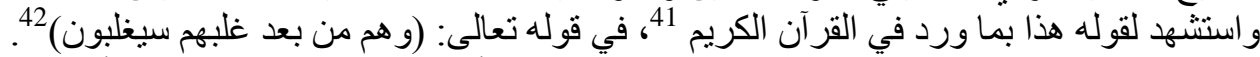

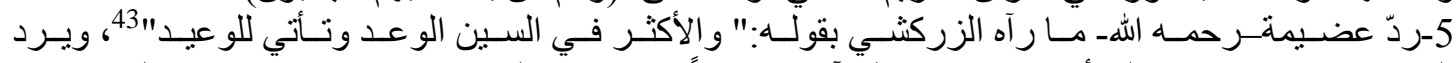

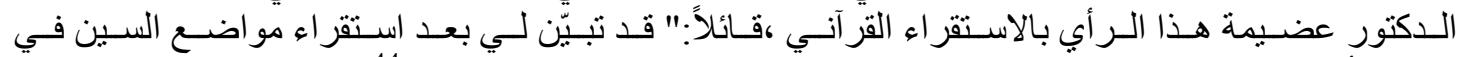

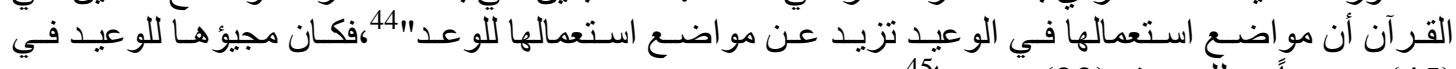

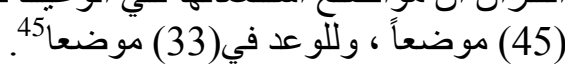

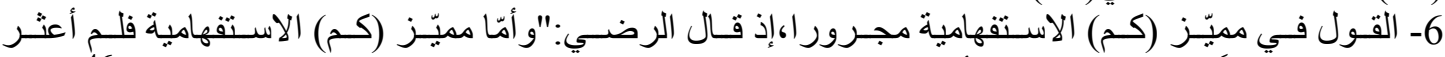

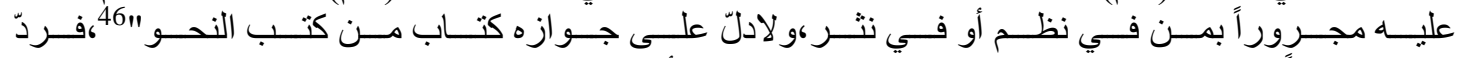

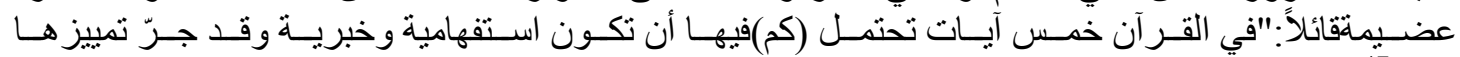

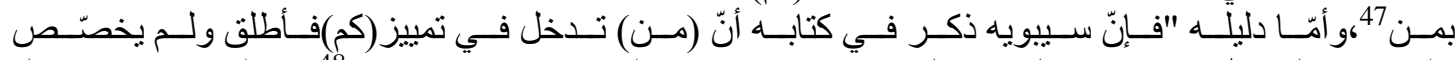

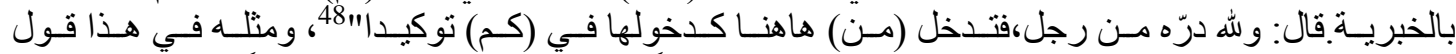

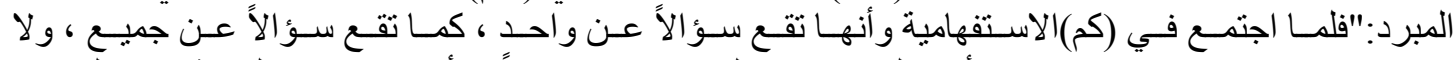

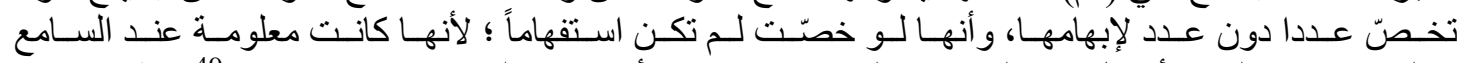

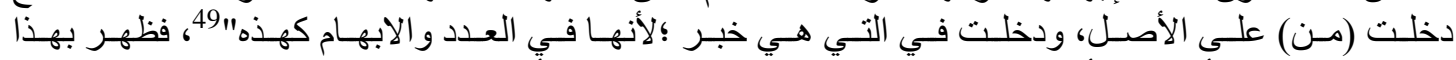

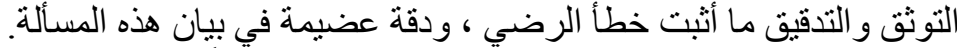

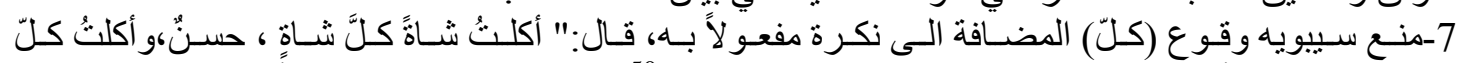

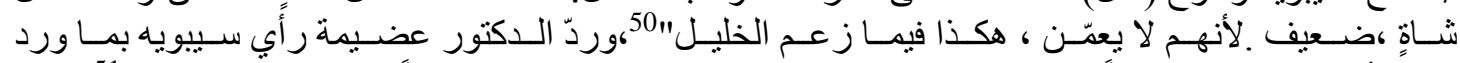

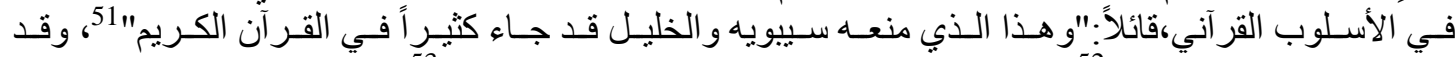

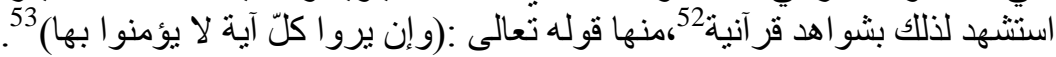




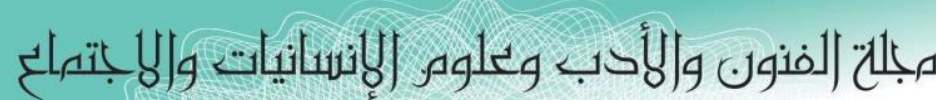
Journal of Arts, Literature, Humanities and Social Sciences

ISSN online: 2414 - 3383

ISSN print: 2616 - 3810

\section{العدد (41) آب - أغسطس 2019}

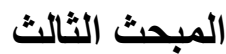

\section{تصحيح أوهام بعض الباحثين في آثار الثيخ عضيمة_رحمه اللهـ وآرائه}

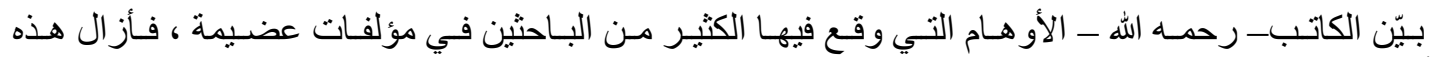

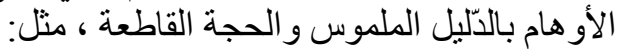

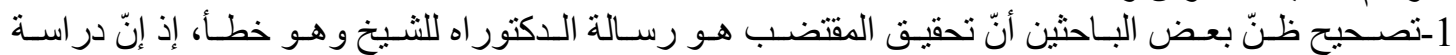

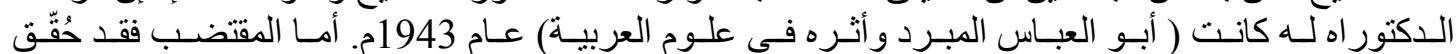

ونشر بين سنة 1963م وسنة 1968 1968م.

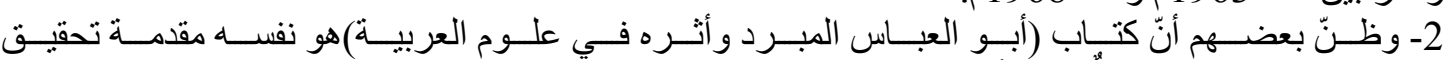

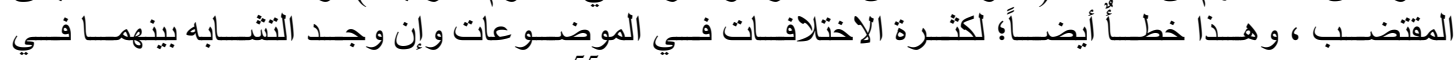

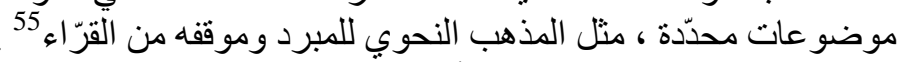

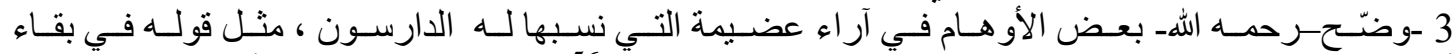

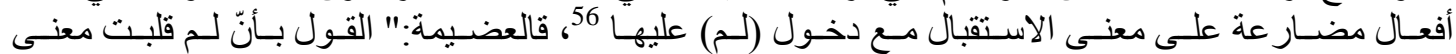

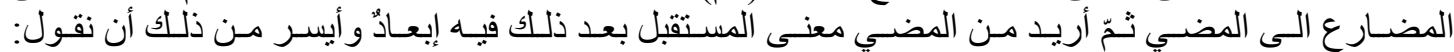

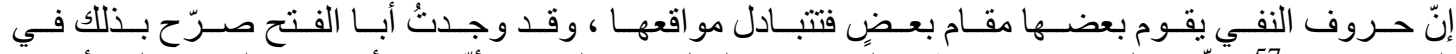

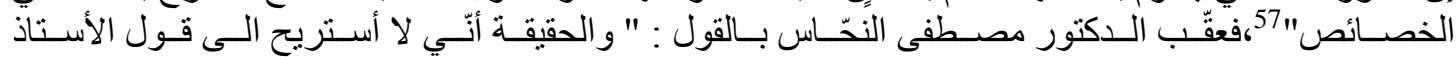

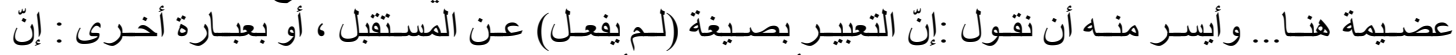

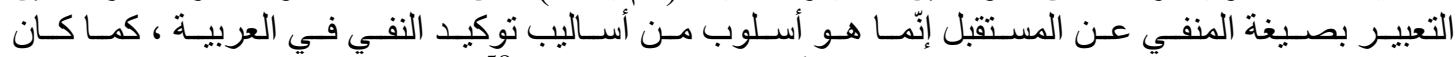

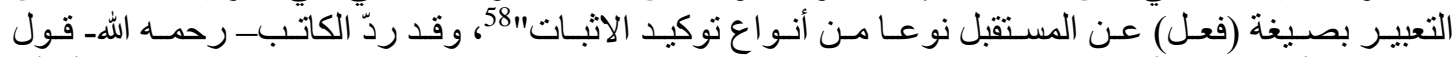

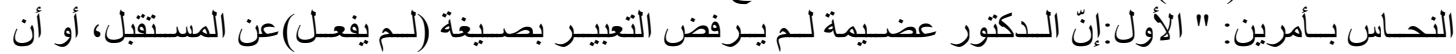

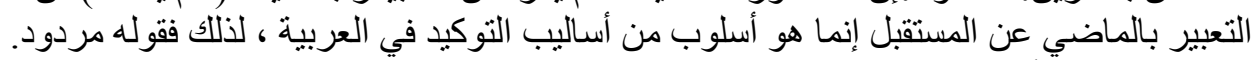

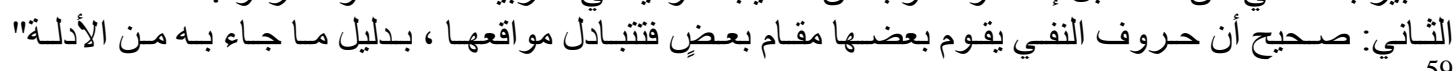

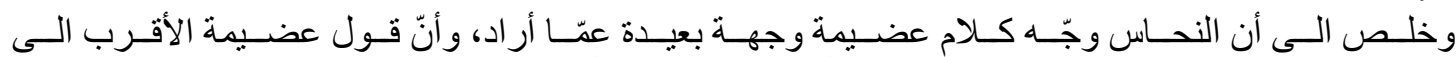

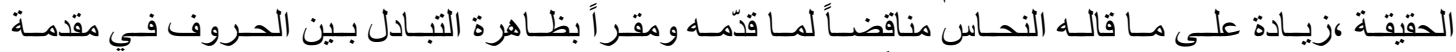

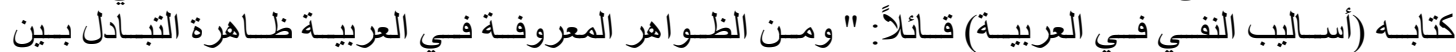

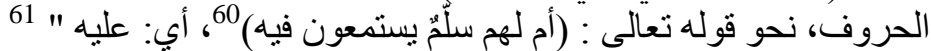

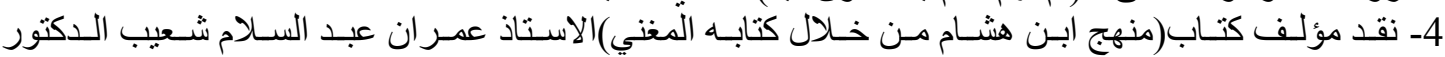

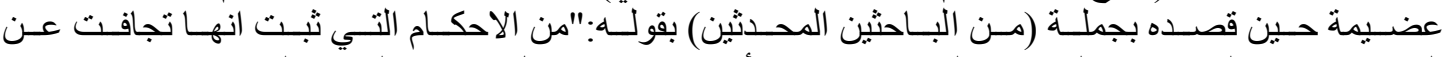

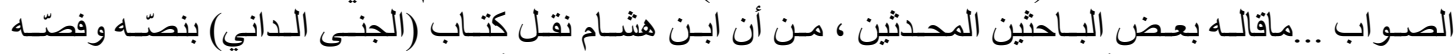

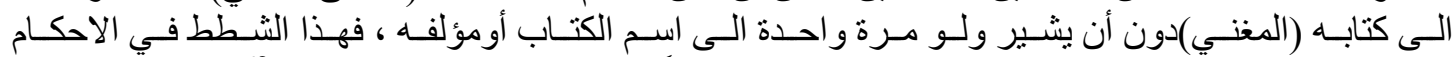

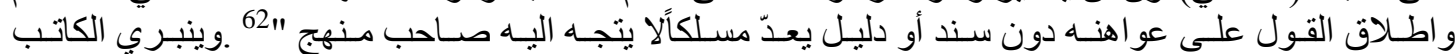

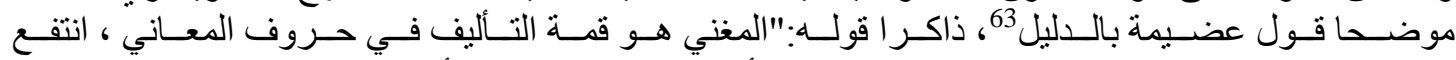

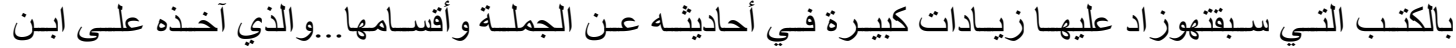

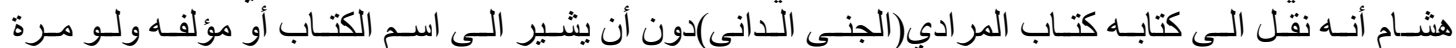

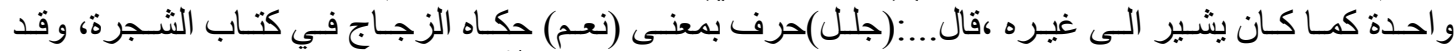

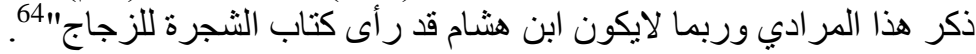

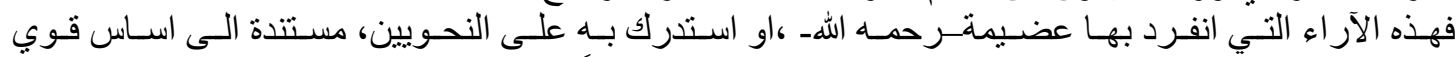

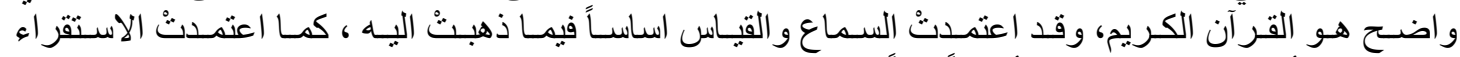
و الاحصاء لأساليب القرآن الكريم أساساً قوياً لها. 


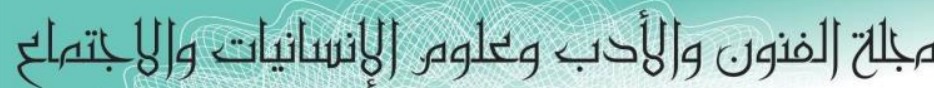

Journal of Arts, Literature, Humanities and Social Sciences

ISSN online: 2414 - 3383

ISSN print: 2616 - 3810

\title{
العدد (41) آب - أغسطس 2019
}

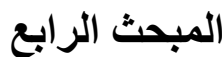

\section{آراء الاكتور كريم أحمد جوادـرحمه اللهـ في هذه الدراسة}

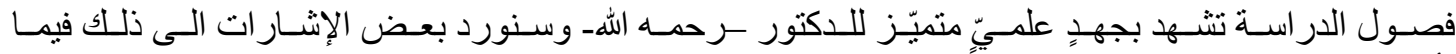

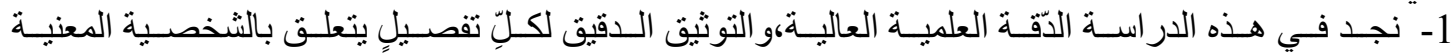

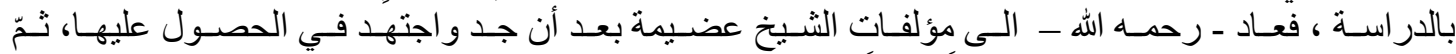

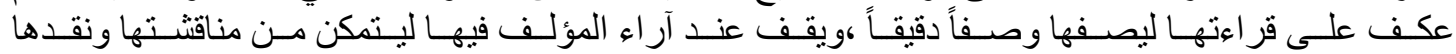

و الدفاع عنها.

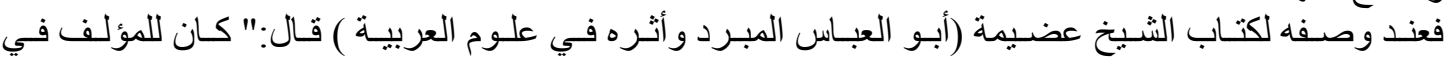

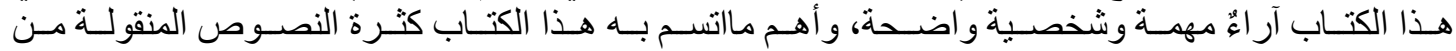

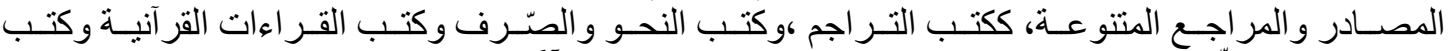

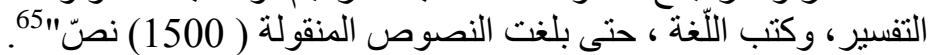

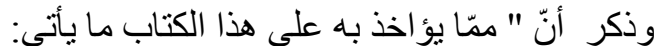

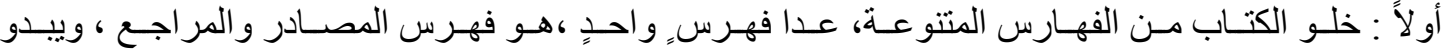

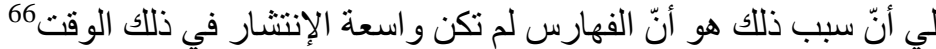

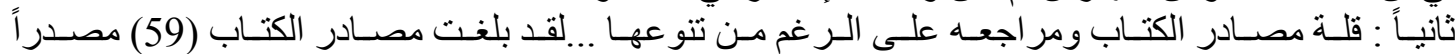

ثالثاً: إنّ الإشارة الىى المصادر والمر اجع في المتن وليس في الهامش ، وهي طريقةٌ تخالف ما ألفناه في التأليف

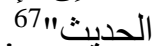
ثثمّ قال:" الكتاب من أنفس ما كتب عن إماٍٍ من أئمة العربية الكبار، وهو المبرد، زد على ذلك أنّها أول در اسةٍ

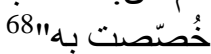
فلم يكن ــرحمه الله ـ ناقلاً أميناً لما في الكتاب فحسب، بل ناقداً مقوّماً ومصحّحاً لأو هام تثعلق بعضيمة ومؤلفاته وآرائه.

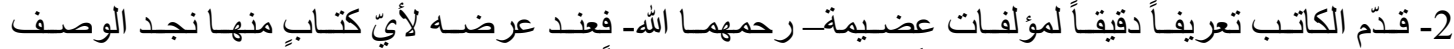

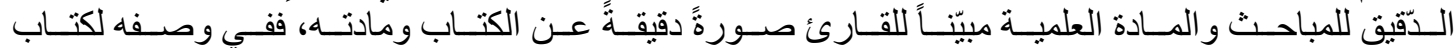

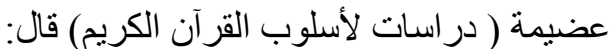

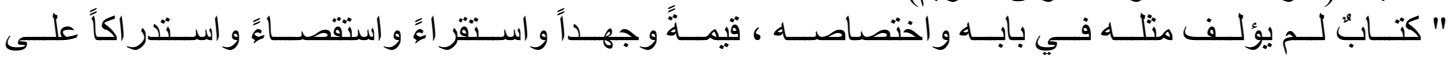

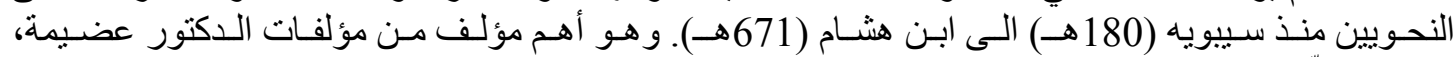

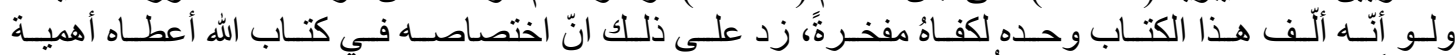

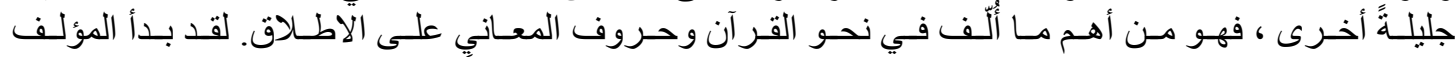

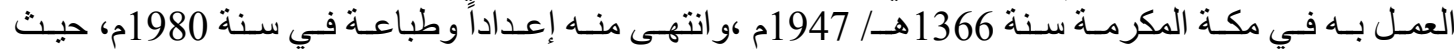

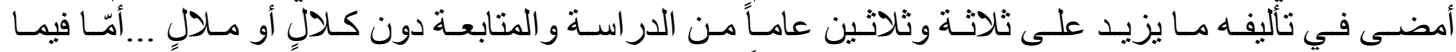

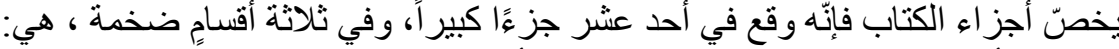

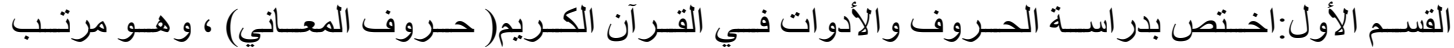

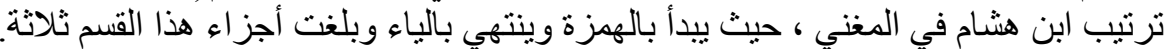

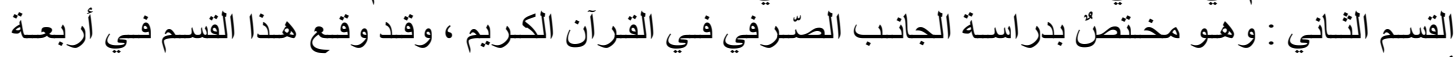
أجزاء.

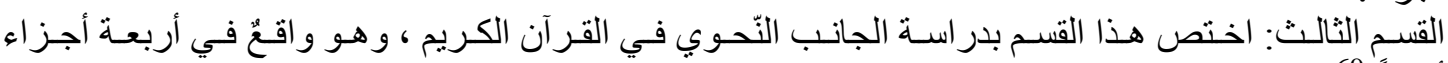
أبضاً" 69

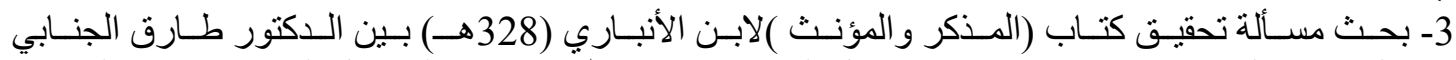

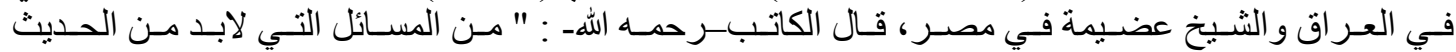

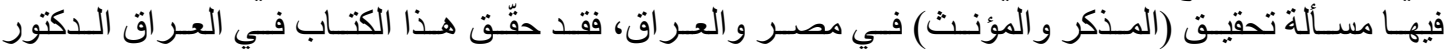




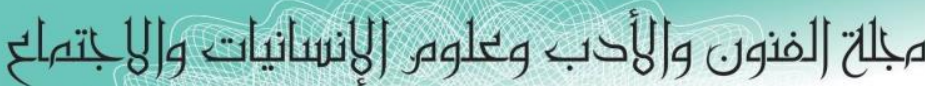

Journal of Arts, Literature, Humanities and Social Sciences

ISSN online: 2414 - 3383

ISSN print: 2616 - 3810

\section{العدد (41) آب - أغسطس 2019}

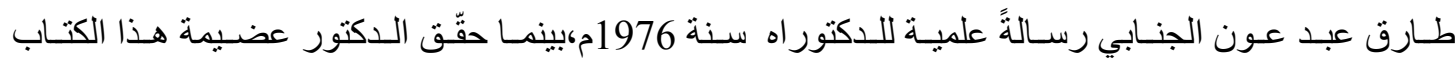

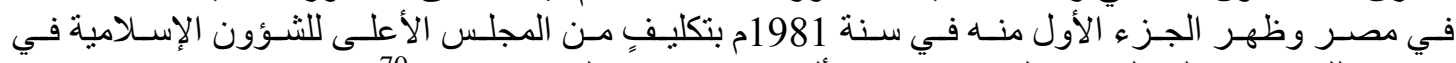

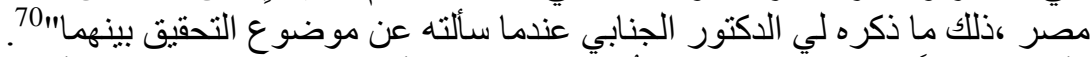

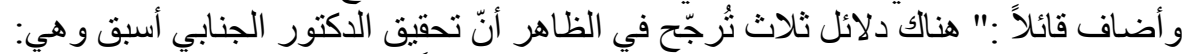

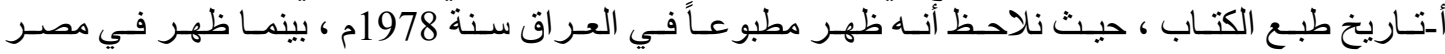

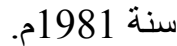

ب - عدم اكتمال الجز اء الثاني من الكتاب في المجلس الأعلى للشؤون الإسلامية في مصر.

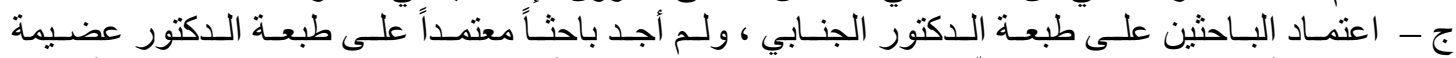

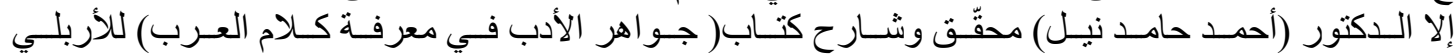

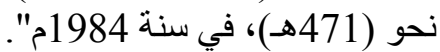

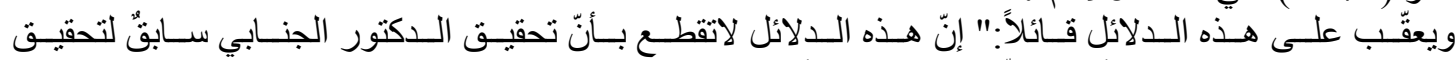

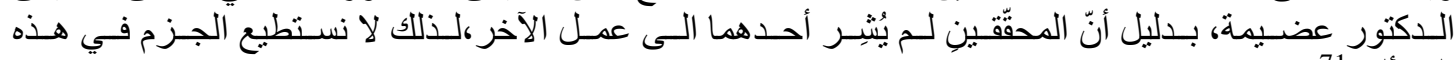
المسألة" المبر

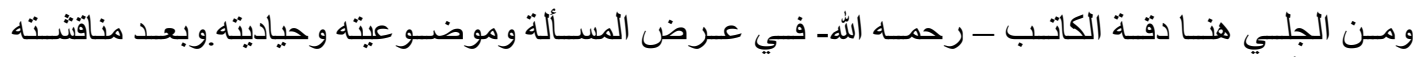

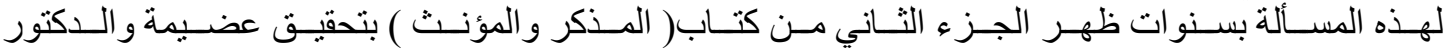

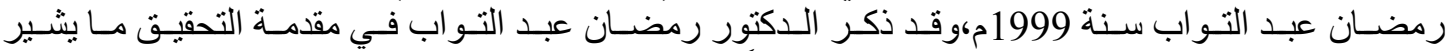

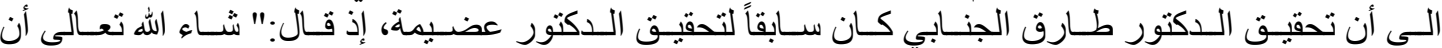

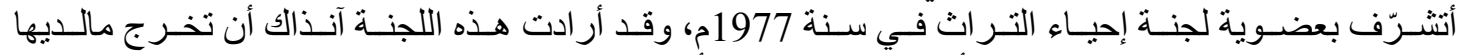

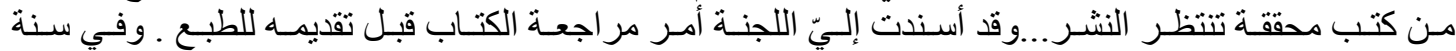

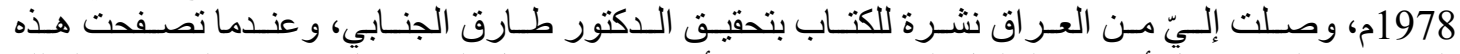

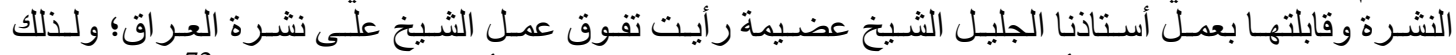

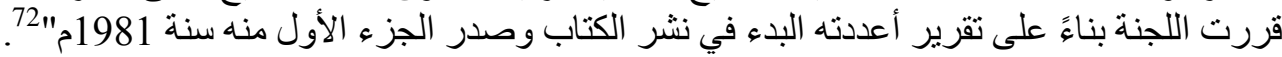

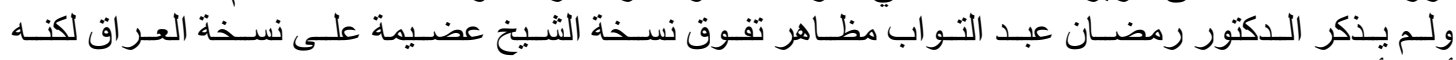

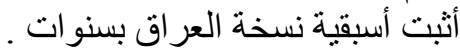

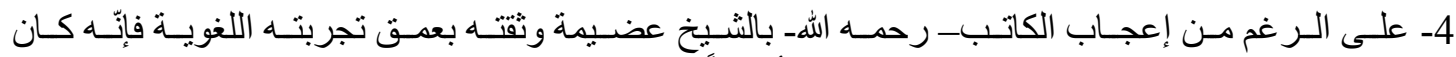

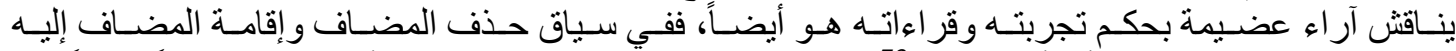

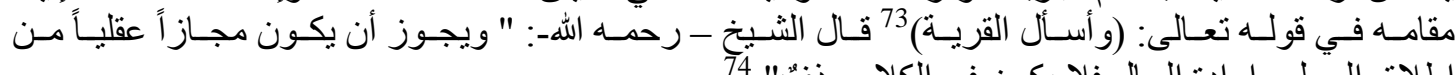
اطلاق المحل و إر ادة الحال فلا يكون في الكلام حذفته

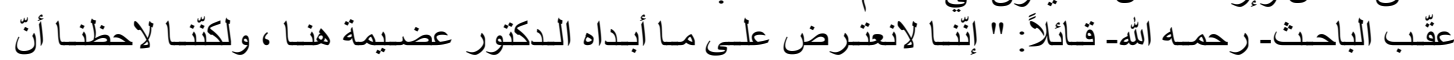

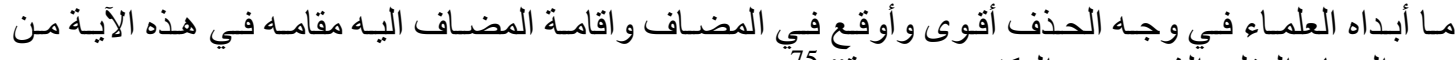

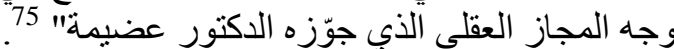

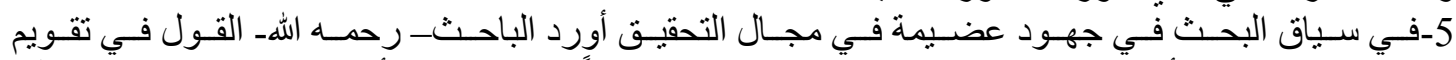

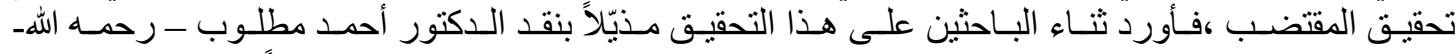

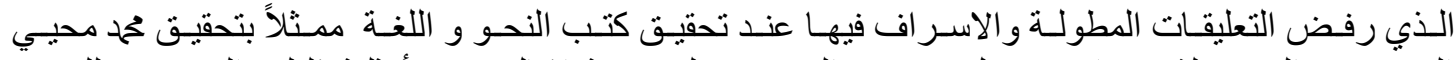

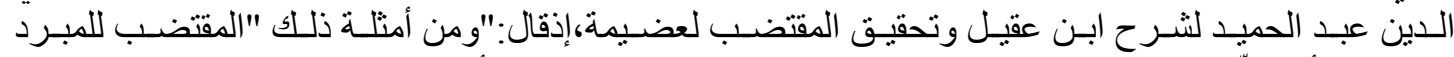

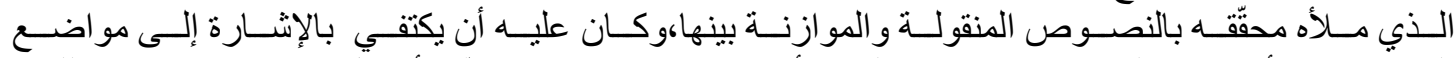

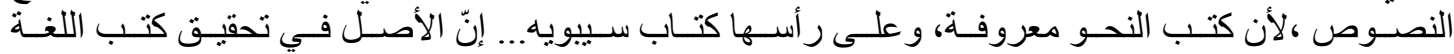

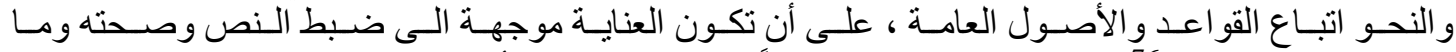

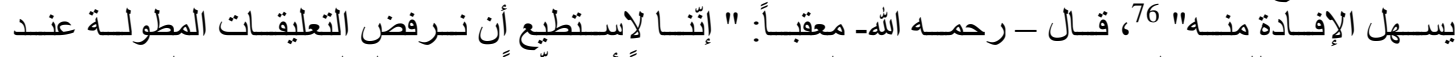

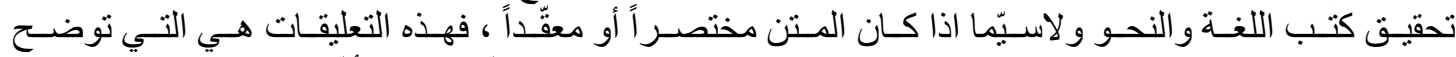

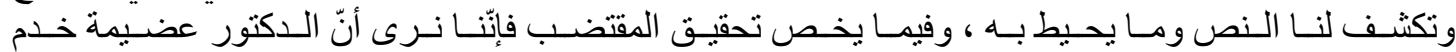

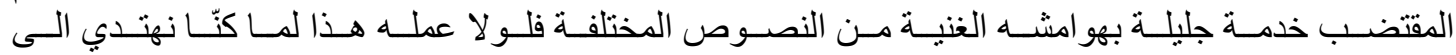




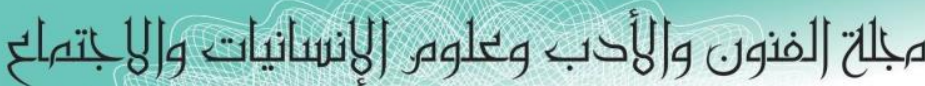

Journal of Arts, Literature, Humanities and Social Sciences

ISSN online: 2414 - 3383

ISSN print: 2616 - 3810

\section{العدد (41) آب - أغسطس 2019}

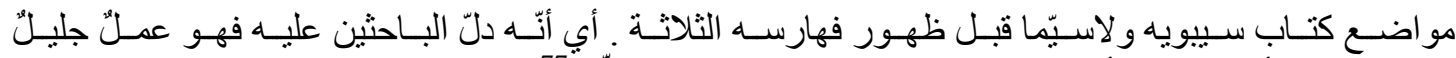

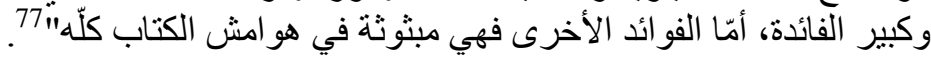

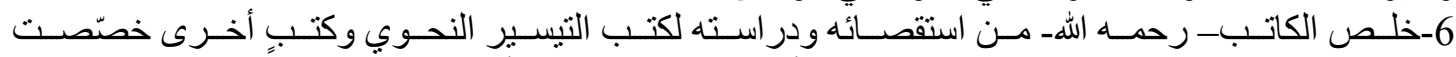

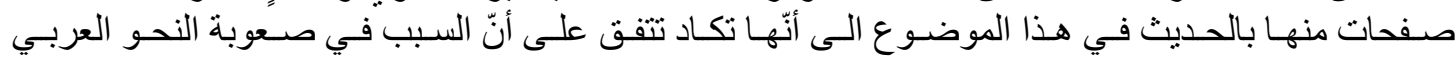

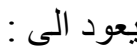

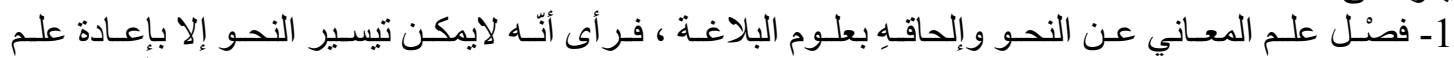

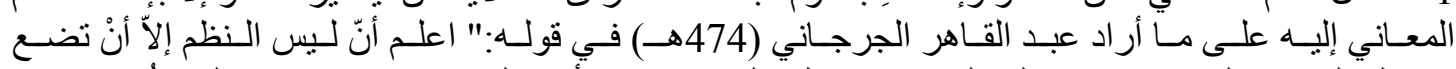

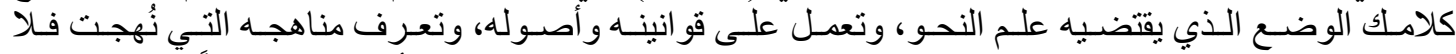

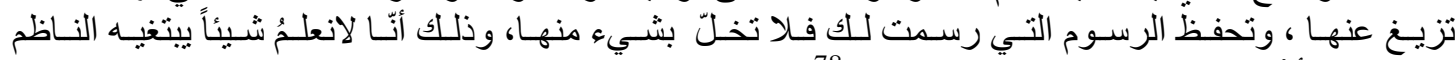

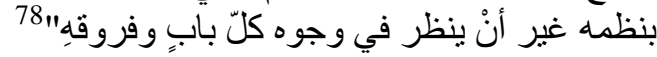

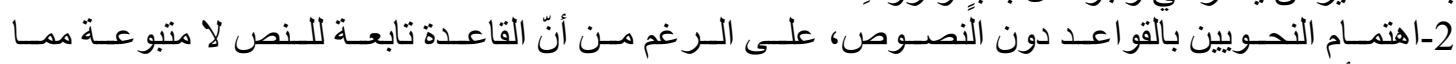
يوجب تأخير ها عنه.

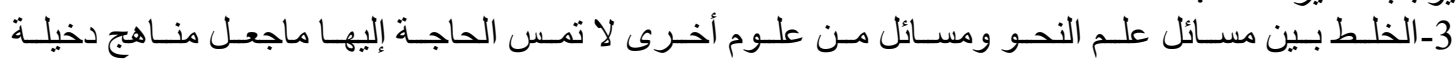
تتسرب إليه كالفلسفة و الفقه و المنطق.

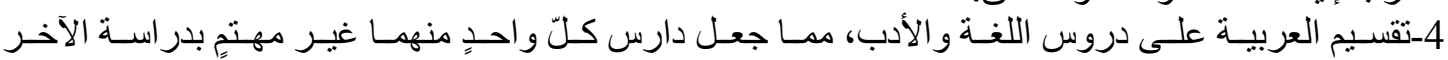

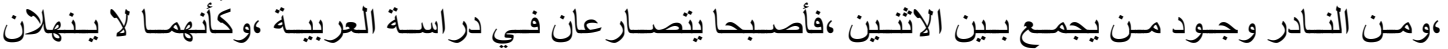

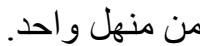

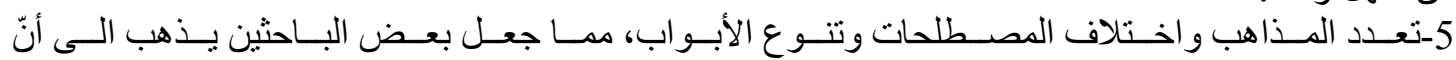
طريقة تصنيف النحو سبب في صعوبته ؛ إذ تبعثرت الحالة الوالو الحدة في أمكنة متفرقة.

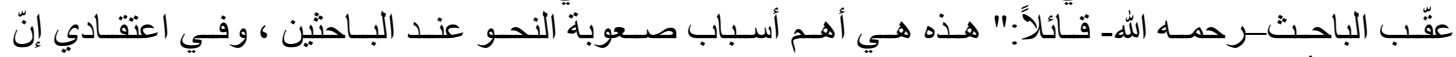

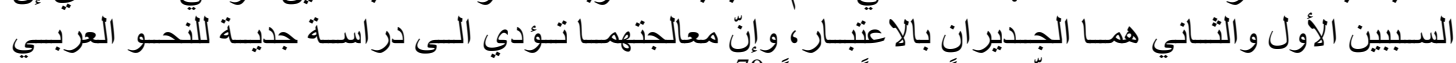

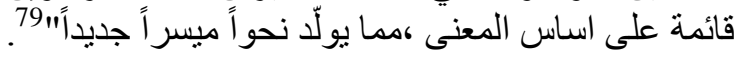

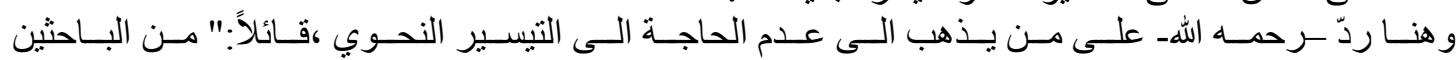

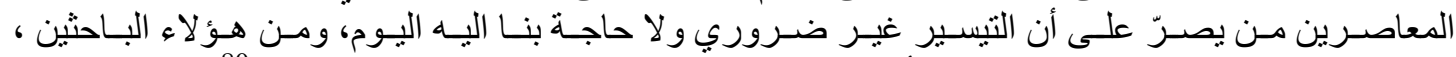

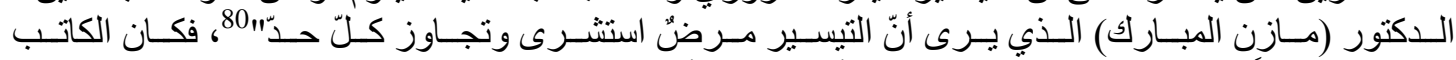

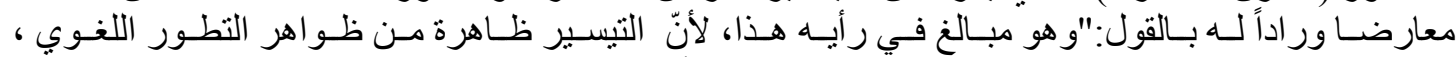

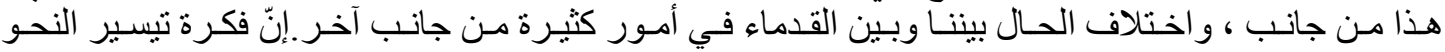

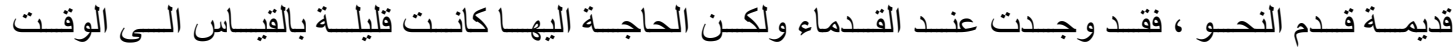

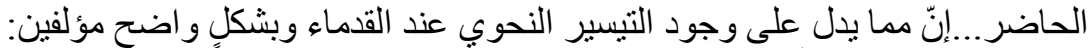

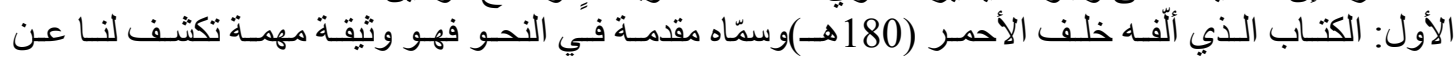

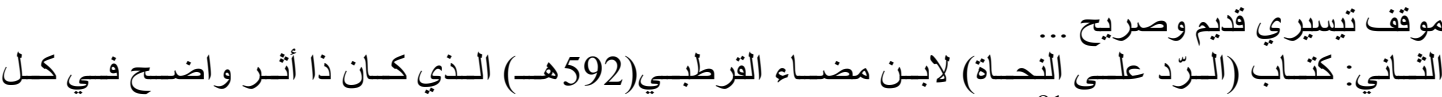
المحاولات التيسيرية الحديثة"

الخاتمة

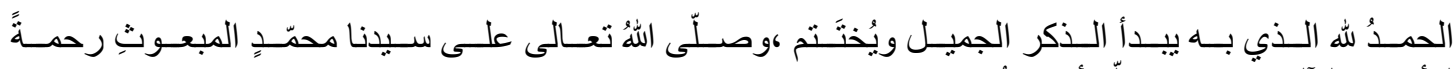

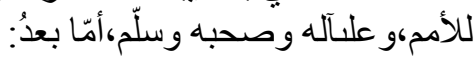

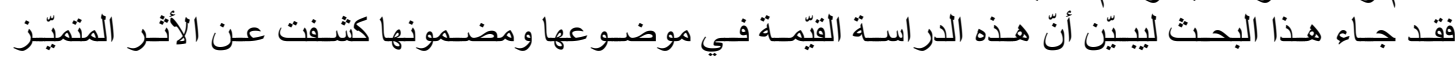

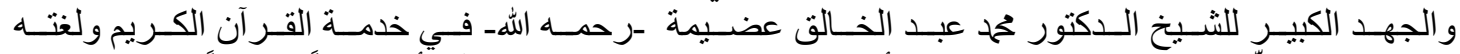

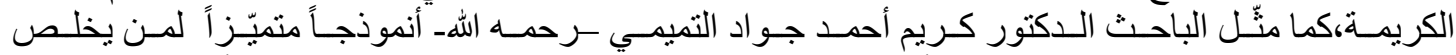
للحقيقة العلمية،فلا يذخر في سبيلها جها أو وقتا،وبعد هذا التناول الموجز خلص البحث الى ما يأتي: 


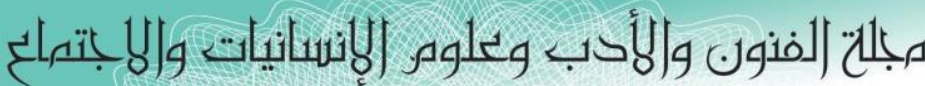

Journal of Arts, Literature, Humanities and Social Sciences

ISSN online: 2414 - 3383

ISSN print: 2616 - 3810

\section{العدد (4) آب - أغسطس 2019}

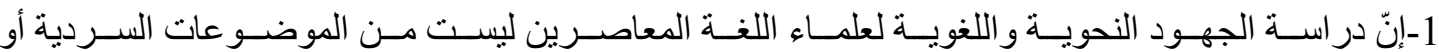

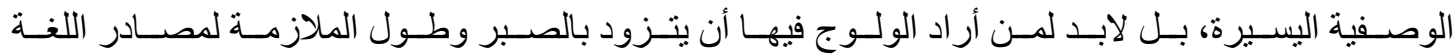

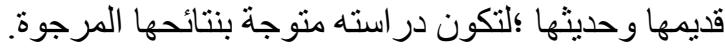

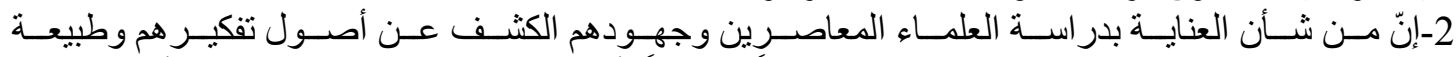

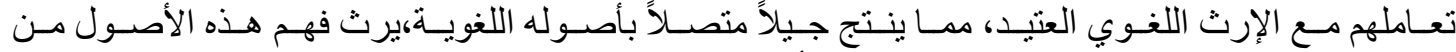

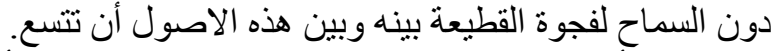

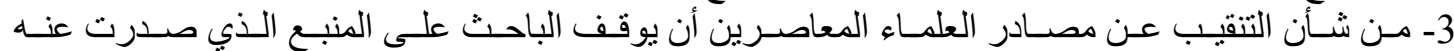

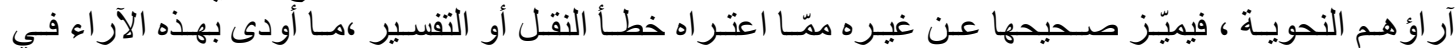
هوة الخلاف الذي لاطائل تحته في مسائل كثيرة.

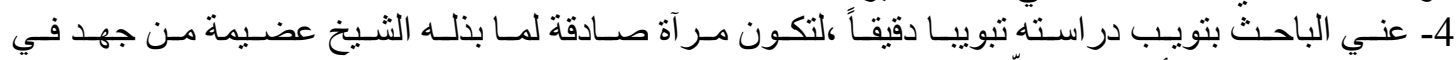

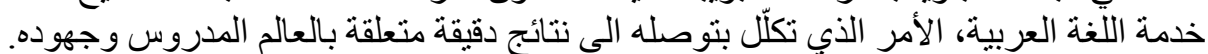

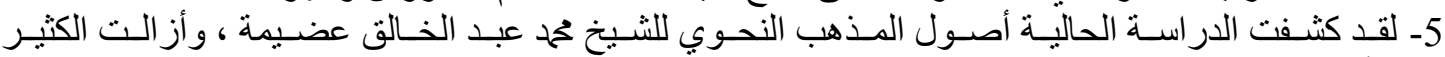
من الأو هام التي كانت مسقطة لعدد من الباحثين المعاصرين ، لاسيما فيمايتعلق بكتبه وآر آئه النحوية.

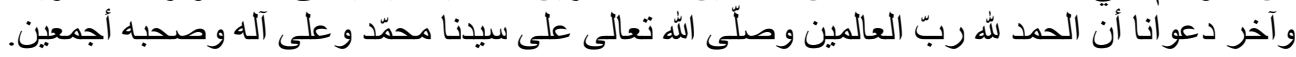

الهوامش

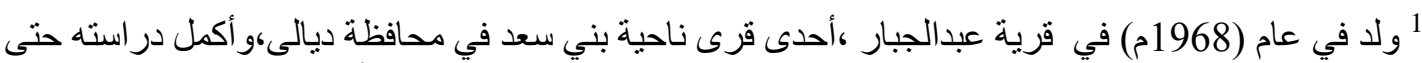

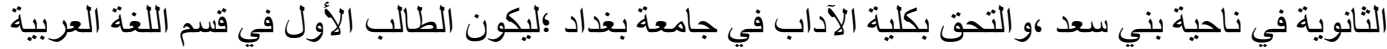

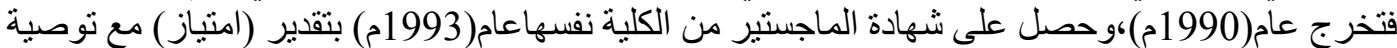

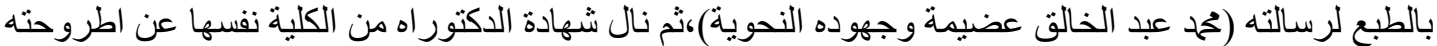

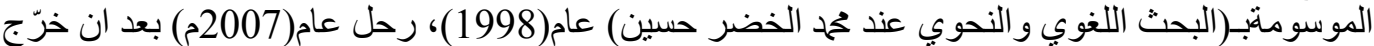

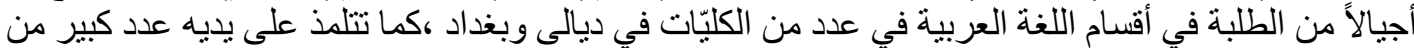

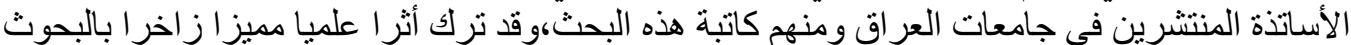

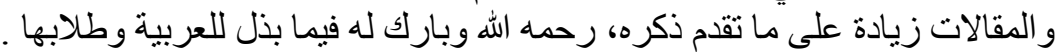

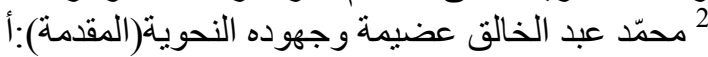

33 ينظر: المصدر نفسه:15-24

(ينظر : المصدر نفسه: 21

5 5مرفة الضاد و الظاء:33

6 لسان العرب( 6 لعضم):476/12

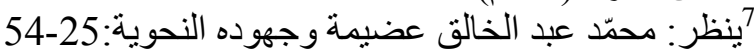

ينظر : المصدر نفسه:

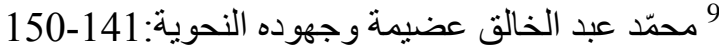

10 1ينظر :المصدر نفسه:127-162-152

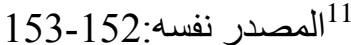

12 ينظر : الكتاب:11 يلفيهر/459،12

13 ينظر : المقتضب: 14 ينظر : مغني اللبيب:15/1-403-84/

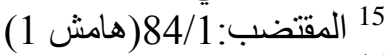
16 الكتاب: 22/2

17 المقتضب:350/3 


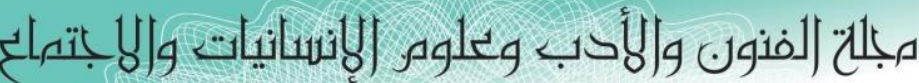

Journal of Arts, Literature, Humanities and Social Sciences

ISSN online: 2414 - 3383

ISSN print: 2616 - 3810

العدد (41) آب - أغسطس 2019

18 المصدر نفسه:350/3-351-(هامش 2)

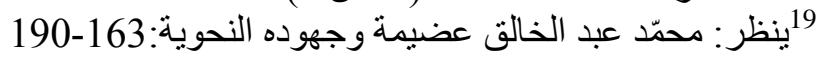

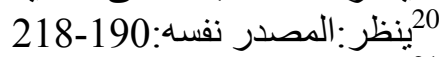

212 20

222 22

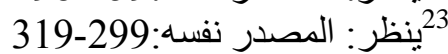

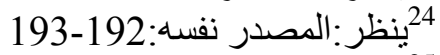

25 البقرة: من الآية 54

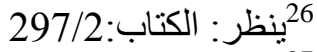

32:الطور

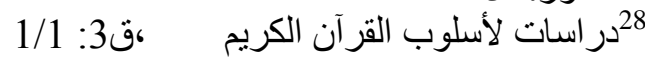

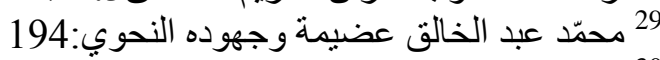

30

3131 3ينظر : البحر المحيط:346/2

11: 11 النسطاء

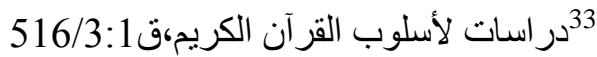

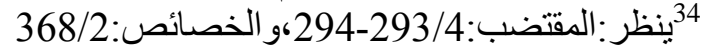

35

36

37 ديو انه:212

38 در اسات لأسلوب القرآن الكريم(ق3):591/3، وينظر : المقتضب:294/4(هامش4)

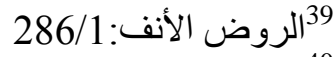

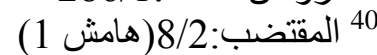

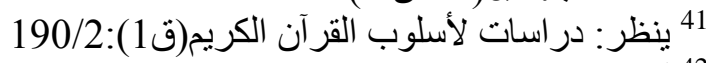

42

434البر هان في علوم القرآن:1098

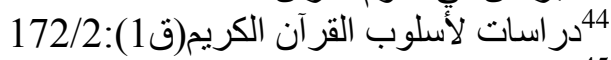

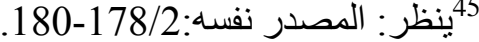

46 شرح الكافية:157/3

47 بنظر :در اسات لأسلوب القرآ آن الكريم(ق1):29 /202-403

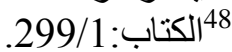

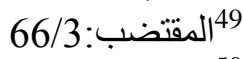

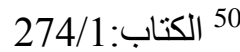

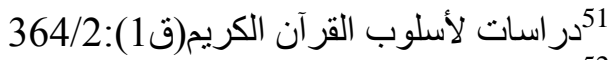

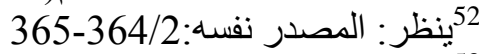

53

54 54 الانغر : ححمد عبد الخالق عضيمة وآراؤه النحوية:59

55 ينظر : المصدر نفسه:

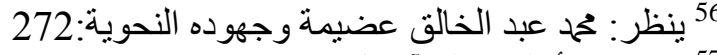

502/2:2 602/

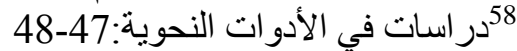

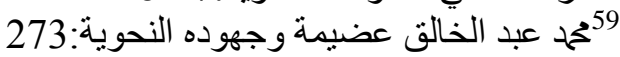




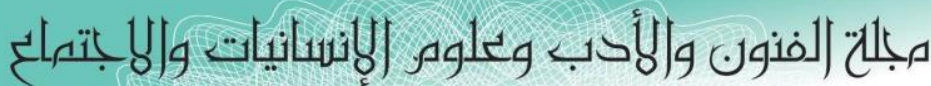

Journal of Arts, Literature, Humanities and Social Sciences

ISSN online: 2414 - 3383

ISSN print: 2616 - 3810

العدد (41) آب-أغسطس 2019

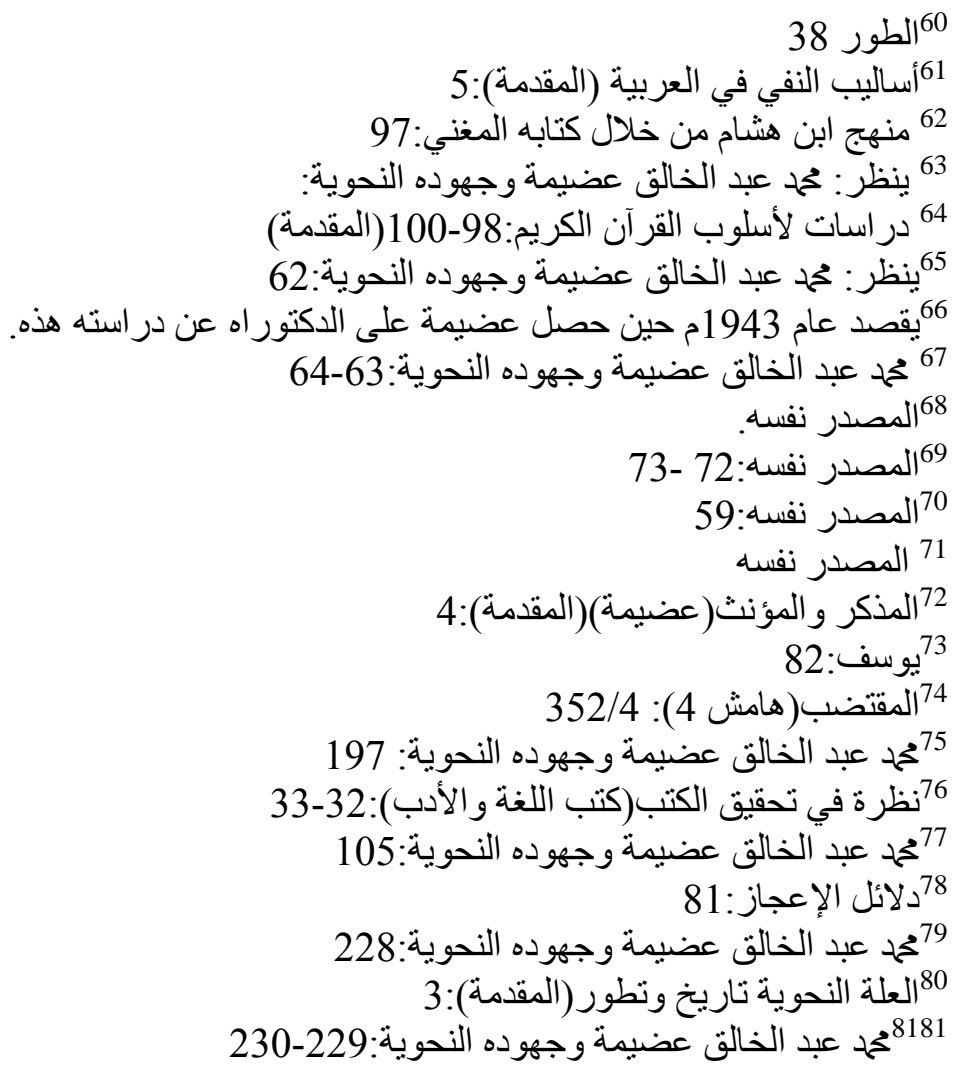

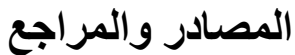

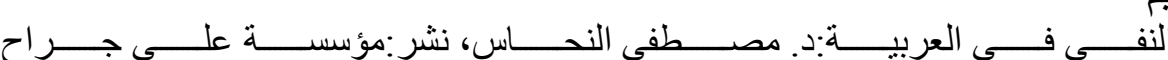

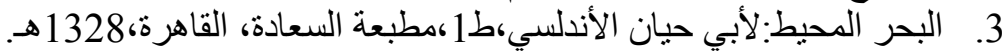

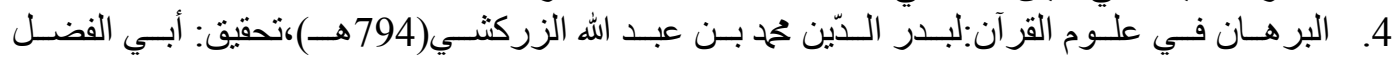

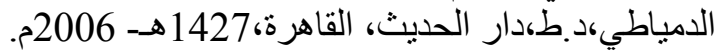

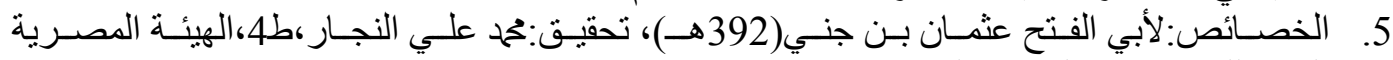

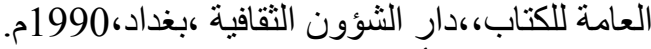

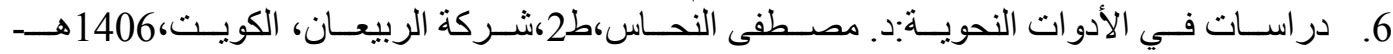

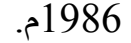

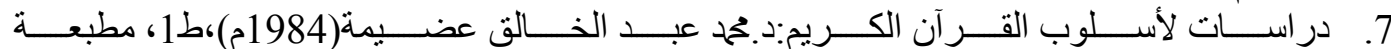

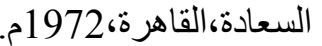

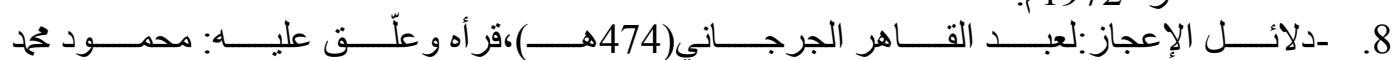

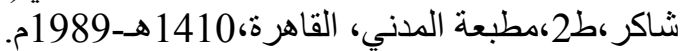

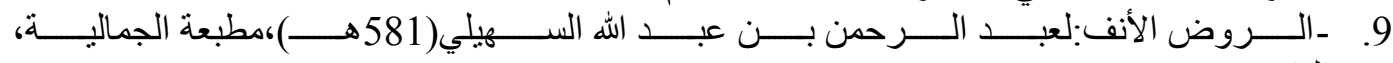

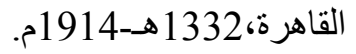




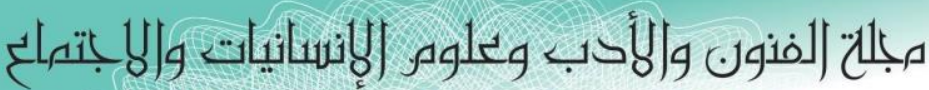

Journal of Arts, Literature, Humanities and Social Sciences

ISSN online: 2414 - 3383

ISSN print: 2616 - 3810

\section{العدد (41) آب - أغسطس 2019}

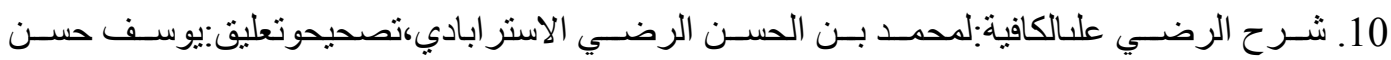

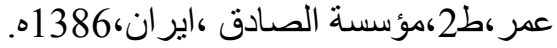

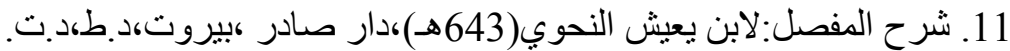

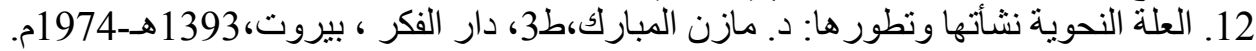

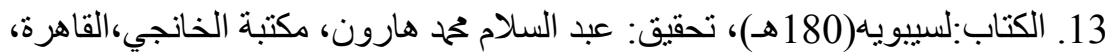

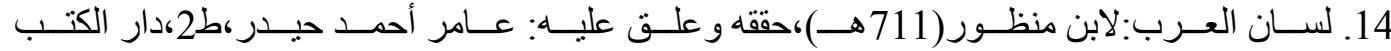

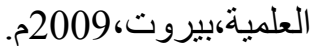

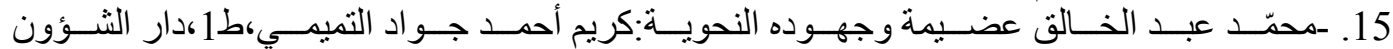

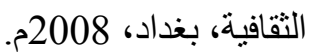

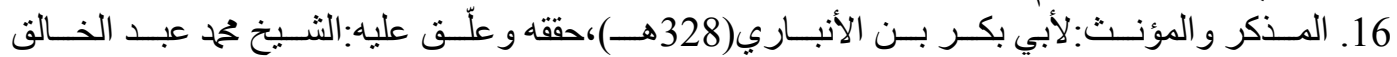

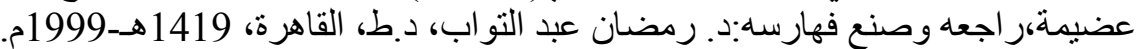

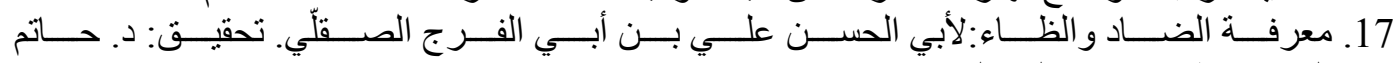

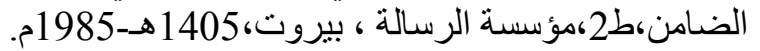

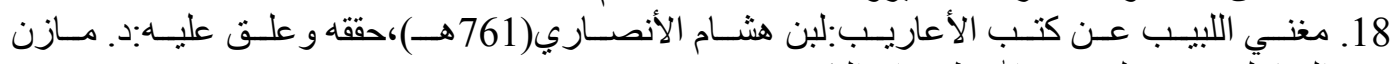

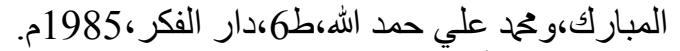

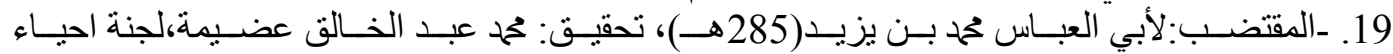
التراث الإسلامي، القاهرة، 1963-1968 1968م.

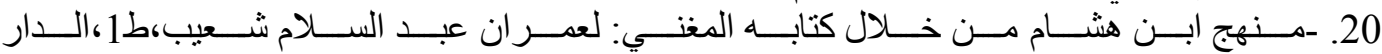

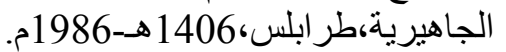

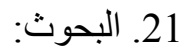

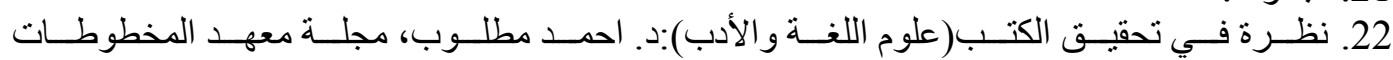

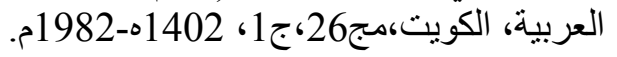

